\title{
EL MONOPOLI DE LA PARAULA: CURA D'ÀNIMES, EDUCACIÓ I FE PÚBLICA \\ A LA PARRÒQUIA DE SANTA MARIA DE PIERA DURANT LA BAIXA EDAT MITJANA'
}

\section{LLUÍS CIFUENTES \\ GEMMA ESCRIBÀ}

Eterna, noble, una paraula

en l'arrelada sequedat..

Salvador EsPriu, Setmana Santa, I

\section{SUMARI}

1. Piera, de vila reial a senyoria eclesiàstica.- 2. El rector, titular de la notaria.- 3. La cura d’ànimes i les seves dificultats a la parròquia de Piera.4. L'escola parroquial i la de gramàtica.

En aquesta col-laboració estudiarem el control simultani exercit pels rectors d'una parròquia catalana dels últims segles medievals sobre tres àmbits: la cura d'ànimes, l'educació i la fe pública. El control simultani d'aquests àmbits, que òbviament no fou exclusiu del cas concret de Santa

\footnotetext{
'Aquesta col-laboració es fonamenta en la documentació sobre la història de la vila de Piera arreplegada pels autors amb la coordinació de Regina Sáinz de la Maza (1996-1998), en compliment d'un projecte finançat per l'Ajuntament per a la pròxima elaboració d'una història del municipi. Volem expressar el nostre agräment per l'acollida que hem tingut en tots els arxius on hem treballat; i també a l'Ajuntament de Piera (en particular a Rosa Escolà i Joan Farrés). Mn. Francesc Mestre, rector de Santa Maria de Piera, Carmel Ferragud, David Nirenberg, Elena Orriols, Jaume Riera, Ron Surtz i Alfons Zarzoso.

Abreviatures emprades: $\mathrm{ACA}=$ Arxiu de la Corona d'Aragó; $\mathrm{ACB}=$ Arxiu de la Catedral de Barcelona; $\mathrm{ADB}=$ Arxiu Diocesà de Barcelona; $\mathrm{AHMP}=$ Arxiu Històric del Monestir de Pedralbes; AMP = Arxiu Municipal de Piera; APP = Arxiu Parroquial de Piera; "BRABLB" = "Boletín de la Real Academia de Buenas Letras de Barcelona": CODOIN = Colección de documentos inéditos del Archivo General de la Corona de Aragón, publ. per Pròsper DE BOFARULl I MASCARÓ et al.: "EHDAP" = "Estudios Históricos y Documentos de los Archivos de Protocolos" (i la seva continuació en català).
} 
Maria de Piera, possibilitava a la parròquia l'exercici d'un autèntic monopoli de la paraula en els camps espiritual, formatiu i notarial. Treballarem amb informació ja coneguda, però, sobretot, donarem a conèixer un gruix de documents que tenim per inèdits o per no degudament localitzats que, per la seva quantitat i qualitat, sí que en fan un cas d'especial interès.

En la introducció presentarem les línies generals de la història de la vila de Piera durant la Baixa Edat Mitjana, centrant-nos en els canvis de jurisdicció que condicionaren tota la vida local, i oferirem un nou rectorologi de la parròquia durant aquell període. Tot seguit estudiarem la possessió per part de la parròquia de l'escrivania pública, els intents del rei (o del senyor del lloc) d'ignorar-lo i la lluita dels rectors per mantenir-lo, alhora que en definirem l'abast. En el següent capítol farem un breu repàs a l'activitat bàsica de la parròquia, la cura d'ànimes, centrant-nos sobretot en els seus aspectes materials. Finalment, estudiarem l'existència d'una escola parroquial i d'una altra de gramàtica, i les relacions entre ambdues.

\section{Piera, DE VILA REIAL a SENYORIA ECLESIÀstica}

La vila de Piera, situada estratègicament en el camí de Barcelona a Lleida i Aragó, fou, durant els darrers segles de l'Edat Mitjana, una florent població que prosperà a redòs de la protecció reial, amb una activitat urbana que la féu esdevenir cap de la vall mitjana de l'Anoia. Tot i que per les angoixes de la hisenda reial o altres causes els monarques la cediren a diversos senyors feudals durant alguns períodes, generalment breus, sempre procuraren recuperar-la i no fou fins a 1431 que es produí l'alienació definitiva ${ }^{2}$. El castell de Piera - dit també de Fontanet durant l'Alta Edat Mitjana - i el seu terme, possessió dels vescomtes de Barcelona almenys des de mitjan segle $\mathrm{X}$, passà al domini directe dels comtes de Barcelona l'any

\footnotetext{
2Entre la bibliografia moderna de la història de Piera, vegeu ANDREU DE PALMA DE MallorCa. Santa María de Piera: notas históricas, Igualada, 1942; Ruy VÉlEz, El castillo de Piera y los palacios de Barcelona del Real Patrimonio de la Corona de Aragón, Barcelona, 1946; i Antonio EsCUDERO I COSTA, El terme municipal de Piera, Piera, 1981. Són útils també els articles de Vicenç CARBONELL I VIRELLA i Pere CATALÀ I ROCA a Els castells catalans, V. Barcelona, 1976, pp. 294-315; Antoni Escudero I COSTA a Història de l'Anoia, II, Manresa, 1988, pp. 79-103, i a Història de les comarques de Catalunya: Anoia, II, Manresa, 1990, pp. 88-94; i Albert BENET I Clarà et al. a Catalunya Romànica, XIX, Barcelona, 1992, pp. 313, $344-45$ i $453-57$.
} 
1063, per la permuta efectuada entre Ramon Berenguer I i el vescomte Udalard II amb el de Pierola ${ }^{3}$.

Jaume I cedí la vila, pel testament de 1265, al monestir de Poblet. Pere el Gran no complí aquesta clàusula testamentària. Alfons el Franc, en canvi, la féu efectiva (1286) però amb la condició que el monestir reconegués el dret del rei a una possible permuta en els cinc anys següents. El rei aprofità aquesta clàusula i arribà a un acord amb Poblet (1287): considerant necessari que continués formant part del patrimoni reial per així millor defensar el camí principal de Barcelona a Cervera dels malfactors, Piera era retinguda per la Corona, i Poblet obtenia a canvi l'església-hospital de Sant Vicent de la Roqueta, al costat de València, amb els llocs que li pertanyien (Castelló de la Plana, Quart, Aldaia i Montornès de València). Però malgrat la vehement justificació d'Alfons el Franc i la confirmació de Jaume II $(1295)^{4}$, poc durà en el patpimoni reial. Potser empès per les necessitats de la guerra amb Castella, Jaume II lliurà la senyoria de Piera a Ramon Folc VI, vescomte de Cardona (1296). Com sovint solia fer-se, la cessió al Cardona es camuflà de venda, i així ens assabentem del valor, si més no teòric, que hom donava a la vila a últims del segle XIII: Ramon Folc venia al rei tot el que posseïa a Montblanc i al seu terme per 320.000 sous barcelonesos de tern, mentre Jaume II li lliurava Piera en franc alou per la mateixa quantitat ${ }^{5}$. De res no van valdre les protestes dels pierencs ${ }^{6}$. Aquest

${ }^{3}$ Francesc MIQUel I ROSSELl (ed.), Liber Feudorum Maior: cartulario real que se conserv'a en el Archivo de la Corona de Aragón. I. Barcelona, 1945, pp. 346-48, \& 325. Per aquest període, vegeu particularment Josep IGLÉSIES I FORT, La Reconquesta a les valls de l'Anoia i el Gaià, Barcelona, 1963, i els articles citats de Catalunya Romänica.

${ }^{4}$ Vegeu una còpia de la permuta (original del 12-12-1287) a ACA, C. Pergamins, carp. 121 núm. 162, 10-06-1301. Ratificació de Jaume II a ibid., Cartes Reials de Jaume II, caixa 146 , núm. 264, i ibid. reg. 195, fols. 68-68 v. 18-04-1295. Vegeu Agustí ALTISENT, Història de Poblet. Poblet, 1974, pp. 106-09. Sobre el camí d’Aragó, vegeu Ramon Morales, El Cami ral d'Aragó i altres itineraris per la comarca d'Anoia, Barcelona, 1966.

5ACA, C, Pergamins, carp. 143, núm. 725, 09-11-1296. El document duu una nota posterior indicant que fou cancel-lat a instància del veguer de Barcelona el 13-12-1320 (vegeu la nota 9).

"ACA, C, Pergamins, carp. 143, núm. 729, 10-11-1296. És una acta de nomenament de síndics i procuradors de la vila per a tractar amb el rei determinats afers que no s'especifiquen i que podem deduir. El document duu els noms dels reunits en assemblea. 
cop el lliurament de la plena possessió del castell, la vila i el seu terme fou immediat ${ }^{7}$.

Però Jaume II aprofità la primera ocasió per recuperar el patrimoni alienat. Just abans d'acabar el segle (1299), el rei es féu revendre el castell i la vila per part del Cardona. Ara, però, el preu a pagar per la tresoreria reial ascendí a 370.000 sous, més un violari de 5.000 sous anuals, la renúncia, mentre visqués Ramon Folc, a ingressar totes les rendes reials de la vila, que aquest es retingué, i la cessió al mateix, també vitalícia, de la vila d'Igualada ${ }^{8}$. El vescomte de Cardona morí el 1320, i aleshores el rei recuperà el ple domini sobre Piera". Sabem que les condicions de la donació

\footnotetext{
${ }^{7}$ ACA, C, Pergamins, carp. 143, núm. 736, 13-11-1296. Acta signada per l'escrivà Pere Abril, en nom del notari de Barcelona Pere Marc, donant fe que Bertran de Canelles, procurador de Jaume II, ha lliurat en nom d'aquest a Ramon Folc, vescomte de Cardona, la plena possessió del castell. la vila $\mathrm{i}$ el terme de Piera, venut pel rei al dit vescomte. El document descriu com es féu la transmissió: un cop cridats tots els homes de la vila $i$ el terme de Piera a toc de campanes de l'església de la vila i pel so del corn, tal com era costum, aquells es reuniren a l'església i allí els foren llegides pel dit escrivà la carta de procuració i la carta de venda de la vila al vescomte $i$, fet això, el vescomte, allí present, demanà al dit procurador que li lliurés la possessió del castell i de la vila, i el dit procurador anà al castell i tancà les seves portes, i després tornà a obrir-les i prenent el vescomte de la mà l'introduí dintre del castell i li'n donà les claus de les portes. Tot seguit, agafant el vescomte de la mà, el féu pujar a la part superior del castell, i contemplant des de la torre tot el terme de la vila, digué al vescomte que li lliurava la possessió del castell. de la vila i del seu terme. A continuació, el vescomte féu posar a la part superior del castell un penó amb el seu senyal, i féu cridar als seus homes en veu ben alta: "Cardona!, Cardona!, Cardona!" moltes vegades, mentre a altres els feia sonar trompes. Després, el procurador i el vescomte tornaren a l'església, i allí el primer manà als homes que hi eren reunits que tinguessin el dit Ramon Folc pel seu senyor i que li’n fessin homenatge, $i$ els dits homes (el document en dóna la llista completa), així ho feren.

${ }^{8} \mathrm{La}$ venda, amb la promesa de cedir-li vitalíciament la vila d'Igualada, a ACA, C, reg. 25 , fols. 147-148, 02-12-1299, fou precedida per un conveni entre el rei $\mathrm{i}$ el vescomte pel traspàs de Piera per la mateixa quantitat que aquest havia pagat el 1296 (ibid., Pergamins, carp. 143, núm. 726, 09-11-1299). La cessió d'Igualada a ibid., fols. 148 v.-149, 02-12-1299. L'últim termini dels 370.000 sous fou pagat per rei l'any 1305 (ibid., Pergamins, carp. 170, núm. 2197. 05-08-1305). El violari fou traslladat a les rendes de Vic, Berga, Santpedor i Gurb l'any 1303 (ibid., reg. 313, fol. 118, 10-01-1303, on hom trobarà la resta de la informació). L'any 1315 les rendes reials a Piera pujaven a 12.000 sous anuals i les d'Igualada fins a 3.000 (ibid., Vària de Cancelleria, vol. 41/2, fols. 29-44 v., publicat a CODOIN, vol. 12, Barcelona, 1856, pp. $245-46$, i vol. 39 , Barcelona, 1871 , p. 75).

${ }^{9}$ Vegeu la notificació al veguer de Vilafranca del Penedès $i$ al sotsveguer $i$ batlle reial a Piera, manant que es restablís en tot la situació anterior a la cessió al Cardona (ACA, C, reg. 218, fol. 152 v., 18-11-1320 - tot seguit [fol. 152 v.] hi ha un document idèntic referit a Igualada). Vegeu la nota 5.
} 
al vescomte suscitaren una gran oposició a la vila que, tot i que es reprimí, obligà el rei a jurar que no tornaria a alienar-la del domini reial ${ }^{10}$.

Així continuà fins a la guerra de Castella, dita dels Dos Peres (13561369). Són conegudes les dificultats econòmiques de la hisenda reial durant aquell llarg i penós conflicte, les terribles calamitats coetànies, i les conseqüències de tota mena que comportà. En aquell context, la jurisdicció directa sobre Piera fou novament moneda de canvi. El mateix any 1364 que el rei de Castella posà setge a València, Pere III va vendre Piera i Igualada al pretendent Enric de Trastàmara per 80.000 florins d'or d'Aragó" ${ }^{11}$. Amb el resultat de la guerra cada vegada més evident, Pere III decidí recuperar el domini sobre uns llocs tan estratègics, i evitar que quedessin en mans d'un pretendent castellà que aviat esdevindria Enric II de Castella. Així s'entén la donació solemne en feu honorat efectuada pel Cerimoniós al seu fill menor, l'infant Martí, encara sota tutoria, de la vila de Piera i dels castells i llocs de Subirats i Sant Martí de Subirats, a la vegueria de Vilafranca, paral-lela a la creació al seu favor del comtat de la Plana $(1368)^{12}$. Amb l'assassinat de Pere I de Castella, la consegüent coronació del Trastàmara (1369), i les desavinences amb el nou rei castellà, el consell reial decidí la incautació de Piera i Igualada' ${ }^{13}$. No obstant això, el Cerimoniós no aconseguí la renúncia formal de Pero Jordán de Urríes, cavaller aragonès que era el seu majordom al qui Enric de Trastàmara havia subinfeudat la vila (1366), fins a l'any 1377 i a canvi d'una indemnització de 50.000 sous $^{14}$.

\footnotetext{
${ }^{10} \mathrm{ACA}, \mathrm{C}$, reg. 218 , fols. 150 v. (Piera) i 151 (Igualada), 18-11-1320. Igualment, el rei renuncià a tots els processos incoats o per incoar per aquesta causa contra els de Piera (ibid., fols. 151 v.-152) i els d'Igualada (ibid., fol. 152).

"L'acta de la venda a ACA, C, reg. 996, fols. 36 v.-39 v., 05-10-1364. La notificació al veguer de Vilafranca, esmentant explícitament les necessitats pecuniàries com a causa de la venda, a ibid., reg. 1195, fols. 161 v.-162, 05-10-1364.

${ }^{12} \mathrm{ACA}, \mathrm{C}$, reg. 915, fols. 35 v.-37 v., 10-03-1368. El que més tard seria rei Martí I tenia aleshores 12 anys; Pere III, en la donació, li assignava com a tutora la seva mare, la reina Elionor de Sicília.

${ }^{13} \mathrm{ACA}, \mathrm{C}$, reg. 1227, fol. 23, 26-04-1369: ordre al batlle general de Catalunya perquè vagi personalment a Piera a prendre'n possessió en nom del rei, i a rebre'n jurament i sagrament d'homenatge, obligant els seus habitants per la força si calgués (n'inclou una altra al veguer de Barcelona $\mathrm{i}$ a tots els oficials reials perquè posin a la seva disposició les. forces militars que tinguin).

${ }^{14}$ ACA, C, Pergamins, carp. 292, núm. 2842, 10-12-1377, pel qual Pero també acceptà la cancel-lació de tots els deutes relacionats amb la guerra que el rei tingués amb ell. La subinfeudació va derivar de l'empenyorament de Piera (ibid., carp. 285, núm. 2473, 17-111366) fet per Enric de Trastàmara pels 15.000 florins del dot de la seva filla Joana, en casar-la amb Pero Jordán, fill del majordom del rei d’Aragó.
} 
Onze anys es mantingué Piera en el patrimoni reial. El 1380 Pere III es va veure en la necessitat de recompensar els serveis prestats pel noble catalanosicilià Guillem Ramon de Montcada, comte d'Agosta i de Nucaria, i el preu va ser Piera, Caldes de Montbui, Granollers, Sant Vicenç dels Horts i la baronia de Cervelló, tot en feu honorat. Els serveis, certament, havien estat de gran importància política: el rapte de la reina Maria de Sicília que, a la mort del rei Frederic III de Sicília (1377), els nobles sicilians regents volien casar contra la voluntat i les conveniències polítiques del rei Pere, i a qui, amb altres barons sicilians fidels, va portar a Catalunya, on més tard fou casada amb Martí el Jove. Mentre Piera fou seva, li fou segrestada dues vegades per l'infant Joan, lloctinent general del rei, fent ús dels drets reconeguts als Usatges $\mathrm{i}$ a les Constitucions de Catalunya ${ }^{15}$. Aquestes intervencions no devien fer-ne rendible la possessió, de manera que el sicilià va optar per renunciar-hi: el 1383 arribava a un acord de permuta amb el comte Pere I d'Urgell, al qui cedí Piera i la baronia de Cervelló a canvi de les baronies de Xiva i de Bunyol i altres llocs que el comte d'Urgell tenia en el regne de València ${ }^{16}$. Poc després Guillem Ramon es dedicà a la pirateria, lucrativa activitat amb la qual intentaria obtenir la relíquia del cap de sant Jordi per al rei Joan I.

Poc abans del Compromís de Casp, el pretendent Jaume d'Urgell va vendre's el castell i la vila de Piera al que havia estat vicecanceller del difunt rei Martí, el cèlebre jurista besaluenc Esperandéu Cardona, per 12.000 florins d'or d'Aragó (1411) ${ }^{17}$. El fill i hereu d'aquest, el cavaller Mateu Cardona, va vendre al rei Alfons el Magnànim (1431), i així Piera, després de mig segle de ser domini senyorial, tornava al patrimoni reial... fugaçment: quatre dies més tard Alfons signava l'acta de venda al monestir de Pedralbes, també en feu honorat. Pressionat el rei per les necessitats de la guerra de Castella, va recórrer a la solució més ràpida per aconseguir fons:

\footnotetext{
${ }^{15}$ La donació a ACA. C. reg. 937, fols. 65-68 v.. 24-07-1380. en compensació pels béns que els nobles sicilians rebels li havien confiscat a l'illa. Els segrestos a ibid., reg. 1800, fol. 47 v.. 31-05-1381 (segrest): ibid. . reg. 1767. fols. 43 v.-47. 16-09-1381 (confirmació); i ibid. . reg. 1634. fol. 231 v.. 24-12-1381 (nou segrest).

"La preceptiva confirmació reial a ACA. C. reg. 1284. fol. 16 v., 16-06-1383. La permuta shavia efectuat a Valls el 5 de maig del mateix any.

${ }^{17}$ AHMP. XXIII. Iligall P, núm. 182. 15-06-1411. La preceptiva confirmació del lloctinent del batlle general i procurador dels feus de Catalunya a ACA. RP. Batllia General de Catalunya. vol. 532. fols. 172-179 v.. 08-11-1411. Lacta d homenatge, ja fet al nou rei Ferran I, tambe com a feu honorat, a ibid. C, reg. 2432, fols. 11-12, 07-01-1413.
} 
l'alienació del patrimoni. Aparentment, fou el monestir el qui escollí el castell i la vila de Piera. El preu de venda, la pressa el féu baixar fins a 9.000 florins (99.000 sous barcelonesos). D'aquesta manera, el monestir de Pedralbes completava els drets que havia anat adquirint a Piera des de la seva mateixa fundació, com ara les rendes de les carnisseries (1326), el dret de mesuratge i les lleudes (1327), etc. ${ }^{18}$. Durant la guerra civil, Joan II confiscà Piera - on s'havia refugiat la reina - al monestir en represàlia per haver ajudat els consellers de Barcelona, i la lliurà a Pere Daura (1461). En acabar el conflicte, Ferran II la restituí a Pedralbes, confirmant-li'n tots els seus drets $(1475)^{19}$. Malgrat les protestes $\mathrm{i}$ els intents fallits de retornar al domini reial. Piera va haver d'adaptar-se a la nova situació. De temps, no li'n va faltar: fins a l'extinció de les jurisdiccions feudals, el 1820.

Com la jurisdicció, d'una evolució tan tortuosa com acabem de dibuixar, foren alienats al llarg del temps altres drets reials a diverses institucions o particulars. Ja hem vist com Pedralbes havia estat beneficiari gairebé immediat d'aquestes alienacions. Un dels drets reials més importants que foren alienats a Piera fou el de l'escrivania o notaria. En parlarem detingudament tot seguit. Però abans, tenint en compte que aquest dret fou cedit a la parròquia, creiem d'interès oferir-ne un rectorologi, elaborat a partir de les noves dades aconseguides en la nostra recerca, que limitem al període medieval ${ }^{2 \prime}$.

\footnotetext{
${ }^{8}$ ACA. C. reg. 2920, fols. 167 v.-170 (esborrany). 170 v. -171 (àpoca) i 190-192 v. (venda) 05-05-1431. Nhi ha copies posteriors a l AIIMP i a l AMP. Una clausula concedia a Pedralbes el dret preferent de recuperar tots els héns o drets alienats pel rei Pere a la vila $i$ a la seva batllia. A més a més. Pedralbes es reclamava hereu de Guillem Ramom de Momtcada. Eal rei havia adquirit Piera de Mateu Cardona el primer de maig anterior. i va trametre-hi un procurador amb la comesa de prendrén possessio i de lliurar-la lot seguit al momestir de Pedralbes (ACA. C. reg. 2648. fols. 19-20. 05-05-1431), cosal que aquest electua pocs dies després (AIMMP. XXIII. Iligall P. núm. 182. 10-05-1431). La notificació oficial d"aquestes transmissions als jurats de la vila. comminant-los a obeir els seus nous senyors, a ibid. fol. 20 r.-v.. 05-05-1431. El nomenament de procuradors per part de Mateu Cardona per notificar-ho als jurats a AHMP, XXIII. Iligall P. núm. 182, 01-05-1431. El castell. esdevingut palau reial des del segle XIII. continuà en mans dels Sescorts com a mansionarii tal i com ho havia estat d'ençà de la donació de Jaume I (1265), però des de 1431 sota l'alta senyoria de Pedralbes.

"ANDREu de Palma. Santa Maria de Piera. pp. 80-82, on és extractada laata de restitució.

20Hi recollim els anys en què cadascun és esmentat com a rector. Els guions darrera o davant l’any indiquen la data d inici o de final del rectorat. Els asteriscos signifíquen informació aportada per ANDREU DE PALMA. Somma María de Piera, pp. 121-22. en el seu rectorologi (pp. 121-28), que no hem pogut verificar en la documentacio recopilada per nosaltres. No obstant aixo. en aquest primer rectorologi (fet a partir de la bibliografia a l'abast l'any 1942 i de notes preses abans de les destruccions de la guerra civil) es cometeren alguns importants errors. com
} 


\begin{tabular}{|c|c|c|}
\hline \multicolumn{3}{|c|}{ Rectorologi de la parròquia de Santa Maria de Piera (segles XII-XV) } \\
\hline rector & documentat l'any & altres dades \\
\hline Guillem NN & $1159 *, 1184$ & \\
\hline Pasqual Albert & $\begin{array}{l}1251^{*}, 1252 \\
1277,1280^{*} \\
1282\end{array}$ & $\begin{array}{l}\text { Ms Arbert i Asbert. Germà del } \\
\text { cèlebre jurista Pere Albert } \\
\text { Canonge de Barcelona* }\end{array}$ \\
\hline Ramon Despuig & $1290, c a$. & \\
\hline Galceran de Barberà & $1296,-1316(\dagger)$ & Canonge de Barcelona \\
\hline Galceran Escuder & 1323 & \\
\hline Pere de Cardona & $\begin{array}{l}1325 \\
1326 \\
1327,1328^{*}\end{array}$ & $\begin{array}{l}\text { També dit Codina } \\
\text { Era a Roma. Substituït per Be- } \\
\text { renguer Matoses } \\
\text { Canonge de Barcelona* }\end{array}$ \\
\hline Berenguer d'Ogassa & $1333 *, 1336$ & Sense ordes \\
\hline Pere Reixac & -1337 & \\
\hline Guillem de Torrelles & $\begin{array}{l}1340,1344 \\
1348,1350 *\end{array}$ & $\begin{array}{l}\text { Canonge de Girona i Barcelo- } \\
\text { na, vicari general del bisbe de } \\
\text { Barcelona (1346-1348), doctor } \\
\text { en dret per Lleida (1353), } \\
\text { ambaixador de Pere III davant } \\
\text { el papa (1349-1350), bisbe } \\
\text { d'Osca }(1357-1361) \text {, de Barce- } \\
\text { lona (1361-1369) i de Tortosa } \\
(1369-1379)\end{array}$ \\
\hline
\end{tabular}

ara incloure-hi persones que mai no van ser rectors (com Guillem Roig l'any 1286 que, com veurem, fou notari però no rector, un Guillem Ponç de Fenollet, un fra Nicolau, cardenal del títol de Sant Sixt, o un Antoni Rovira el 1416), ignorar-ne d'altres que sí que ho foren (Ramon Despuig, Galceran Escuder, Pere Reixac, Ramon d'Argençola, Ramon Rovira i Mn. Dorca), confondre'n dos de diferents en una mateixa persona ("Guillem Ramon de Segarra"), o reproduir-hi noms mal llegits ("Oliver Agassà" per Berenguer d'Ogassa, "Guillem de Ferrins" per Guillem de Torrelles, "Arnau de Fons-Fon" per Arnau de Tous o "Baltasar Coris" per Baltasar Corts) 


\begin{tabular}{|c|c|c|}
\hline Ramon d'Argençola & 1363 & El 1377 era rector de Pierola \\
\hline Ramon Rovira & -1363 & Renuncià \\
\hline Pere Isern & $\begin{array}{l}1366,1367 \\
1368,1372 \\
1373,1375^{*} \\
-1376\end{array}$ & $\begin{array}{l}\text { Beneficiat a la catedral i do- } \\
\text { mèstic del bisbe, substituït per } \\
\text { Pere Morató } \\
\text { Cessat }\end{array}$ \\
\hline Guerau Draper & $\begin{array}{l}1376- \\
1378 \\
1381 \\
1382,1385^{*}\end{array}$ & $\begin{array}{l}\text { Abans de Vilabella i Bràfïm } \\
\text { Absent, substituït per Arnau } \\
\text { Terrassola } \\
\text { Absent, substituït per Ramon } \\
\text { Savall }\end{array}$ \\
\hline Arnau de Tous & $\begin{array}{l}1388,1399 \\
1400 \\
1404,1409 \\
1410,1416 \\
1420,1429 *\end{array}$ & Degà provisional \\
\hline Bartomeu de Collell & $1435^{*}$ & $\begin{array}{l}\text { Procurador de Pedralbes el } \\
1431\end{array}$ \\
\hline Francesc Serradell* & 1436 -* & \\
\hline Narcís Dalmau & $1438^{*}, 1465^{*}$ & Canonge de Barcelona* \\
\hline NN Dorca & $?$ & No es féu efectiu? \\
\hline Baltasar Corts & $1466,1479 *$ & $\begin{array}{l}\text { Prevere urgellenc, batxiller en } \\
\text { decrets }\end{array}$ \\
\hline Guillem Segarra & $1481,1484 *$ & \\
\hline Ramon Segarra & $\begin{array}{l}1492,1497 \\
1507 *\end{array}$ & \\
\hline
\end{tabular}




\section{El RECTOR, TITULAR DE LA NOTARIA}

És sabut que, com a pervivència de la baixa romanitat, durant els primers segles medievals les seus episcopals, els monestirs i les parròquies mantingueren (en principi, per als seus assumptes) l'exercici de la notaria o escrivania; tradició que es reforçà i desbordà l'àmbit eclesiàstic en una societat majoritàriament illetrada i amb una institució reial buida de poders. En el pas de l'Alta a la Baixa Edat Mitjana, la reactivació del comerç, el sorgiment de la burgesia i la recuperació de les jurisdiccions reials, determinaren l'aparició d'un nou notariat laic al servei d'aquests tres factors. Un notariat sòlidament emparat per una autoritat reial renovada mercès a la recuperació del dret romà. No obstant això, aquest nou notariat laic no suposà l'eliminació de les notaries eclesiàstiques, sinó que es superposà a aquestes, sovint en obert conflicte i forçant-ne una redefinició ${ }^{21}$. Així, entenent-la com una regalia, un dret inherent a la senyoria, el rei prohibí que la funció notarial fos exercida per eclesiàstics (Aragó, 1247; València, 1283; Catalunya, 1302) i, alhora, començà a concedir (o millor, a confirmar) el dret de notaria a parròquies i monestirs, a canvi del reconeixement de l'origen reial de l'autoritat notarial —manifestat sovint en la imposició de l'exercici del dret per part d'un notari reial. L'equilibri de poders (reial i eclesiàstic) en la funció notarial que en resultà constitueix una singularitat del notariat a Catalunya, on la monarquia es va veure obligada a pactar amb una situació ja molt consolidada: a Aragó i, en especial, a València —un regne

\footnotetext{
${ }^{21}$ Vegeu una bibliografia (fins a 1974) de la historia del notariat català a Josep TRENCHS I ÒDENA. Bibliografia del Notariado en España (siglo XX). "EHDAP", 4 (1974). pp. 193-237: i d'ell mateix. Fucentes impresas para la historia del notariado catalán (siglos XV-XIX). ibid. . 9 (1981), pp. 7-25. Per una síntesi general, ultra els clàssics de Francesc Carreras I CANDI, Desenrotllament de la institució notarial a Catalumya en lo segle XIII. a "I Congrés d'Història de la Corona d'Aragó". II. Barcelona. 1909. pp. 751-89: Victorí SANTAMARIA. Estudios notariales: contribución a la historia del notariado en Cataluña. Barcelona. 1917; i Fèlix DURAN I CAÑAmERAS, Notas para la historia del notariado catalán. "EHDAP". III (1955), pp. 71-207: vegeu els treballs reunits a Josep M. SANS I TRAVÉ (coord.), Estudis sobre históric de la institució notarial a Catalumya en honor de Raimon Noguera, Barcelona. 1988: i IDEM (coord.). Actes del I Congrés d'història del notariat catalì Barcelona, 11, 12 i 13 de novembre de 1993). Barcelona, 1994 (en particular les sintesis d Ignasi BAIGES I JaRDi. El notariat catalì: origen $i$ evolució. pp. 131-66. i Rafael CONDE Y DELGADO DE MOLINA. El pas de l'escrivì al notari. pp. 439-62); i Josep M. PONS I GURI. Recull d'estudis d'història jurídica catalana, 3 vols., Barcelona. 1989 (en particular el treball El testament parroquial giromi en el segle XIV. I. pp. 21-32). El treball més complet sobre el col-lectiu notarial és el de José $M^{\text {a }}$ CRUSELLES Gómez, Comportamiento social y actividad profesional entre los notarios de la ciudad de Valencia (siglo $X V$ ). tesi doctoral inèdita. Universitat de València, 1991 (Barcelona, en premsa).
} 
construït de cap i de nou-, la notaria era radicalment prohibida als eclesiàstics pels Furs ${ }^{22}$.

En aquest context s'inscriu la confiscació de la notaria de Piera efectuada pel batlle general Ramon de Plegamans (mort l'any 1240) al rector Ramon Despuig. Un altre rector, Pasqual Albert, aconseguí negociar a la cort el retorn de l'escrivania a la parròquia i la revocació de qualsevol concessió de la notaria feta a altres persones (1252). És molt possible que en la consecució d'aquest transcendental document no hi fossin indiferents les seves influències familiars: era germà del cèlebre jurista Pere Albert $f$ fl: 1233-1261) i un i altre canonges de la Seu de Barcelona. Ara bé, res no fou ja com abans: a partir d'aleshores el rector hauria de reconèixer la senyoria del rei, manifestada en un cens anual de 2 morabatins alfonsins d'or per Pasqua, el mateix cens que el rector exigiria als notaris als quals arrendés l'escrivania. Així totes dues parts quedaven satisfetes... de moment ${ }^{23 .}$. Sota el rectorat de Pasqual Albert es consagrà el nou temple parroquial (1260), i en l'acta de consagració hom no s'oblidà de fer constar el dret de notaria entre els que posseïa el seu rector ${ }^{2-}$. Pasqual Albert va haver de recórrer a la justícia reial perquè el privilegi fos observat, en particular pel que feia

\footnotetext{
"2Vegeu particularment Antoni M. ARAgó I Cabañas. Concessions reials del Dret de Notaria a parròquies $i$ monestirs catalans (segles XII $i$ XIII). "EHDAP". VI (1978). pp. 1-14: Rafael CONDE Y DELGADO DE MOLINA. La titularidad de las notarías parrocmiales catalanas desde Pedro II (III) el Grande a Jaime II: del Provecto Besalia (I28I) a la Pragmática de 1302. a SANS I TRAVE (coord.), "Estudis sobre historia de la institució notarial". pp. 31-50: M. Teresa FERRER I MALLOL. L'expansió d'una regalia al començament del segle XIV: el notariat reial. "EHDAP". XIII (1995), pp. 55-73; i CONDE Y DELGADO DE MOLINA. El pas de l'escrivia al notari. pp. $452-55$ i $459-61$.

${ }^{23}$ El privilegi reial. amb data 04-08-1252. es troba insert en un altre document posterior (ACA. C, reg. 340, fols. 22 v.-23,06-05-1296), que comentarem tot seguit. Ha estat publicat i comentat per FERRER I MALLOL. L'expansió d'una regalia, pp. 56 i 65-66. \$ 1. Pere Albert havia dictat sentència (1236) contra la titularitat esclesiàstica de la notaria de Terrassa. revocada per un privilegi reial (1254) molt similar al de Piera; vegeu Pere PUIG I USTRELL. Senvoric directa, domini átil i funció notarial a la notaria i l'escrin'ania publiques de Terrassa, a SANs I Travé (coord.), "Actes del I Congrés". pp. 617-33. Sobre el parentiu entre Pere i Pasqual. vegeu Carme BATLLE I GALLART. La casa burgesa a la Barcelona del segle XIII, a "La societat barcelonina a la Baixa Edat Mitjana" I= "Annexos d'Història Medieval d'Acta Mediaevalia". I]. Barcelona, 1983, pp. 9-51, \$4; i Arcadi GarCia I SANZ, El jurista Pere Albert i la sev'a obra, "EHDAP", 14 (1996), pp. 7-38, a la p. 8.

${ }^{24}$ Sobre l'escrivania s'hi fa constar: quam habet ab antiquo, qua etiam sibi a principe est concessa, i es remarca que abastava tot el terme de la vila i castell de Piera, i que el notari que actués a Piera no podia confeccionar cap testament, esponsalici, dotalici o qualsevol altra mena de contracte, sense pagar al rector dos morabatins censals cada any (ADB, Dotaliarum, vol. 7. fols. 249-252, 15-11-1260, còpia del segle XVIII). N'hi ha una altra còpia, de 1630, a l'APP. Ilibre $2 / 2$, núm. 8.
} 
a la revocació d'anteriors concessions. Sabem que el 1282 mantenia un plet amb Guillem Roig, documentat actuant com a notari a Piera ja l'any $1263^{25}$.

El projecte de reglamentació de totes les escrivanies de la Corona d'Aragó, tant laiques com eclesiàstiques, de Ramon de Besalú (1281) consagrà i generalitzà, quant a les notaries parroquials, la situació dibuixada en el privilegi de 1252. Suposà, això sí, una nova onada de confiscacions de drets de notaria de titularitat eclesiàstica que, tot i que no fou lineal i el rei es va veure obligat a reconèixer l'statu quo a les corts de Barcelona de 1283, molt probablement explica que el rector de Piera Galceran de Barberà fes per obtenir la confirmació de Jaume II (1296) del privilegi de $1252^{26}$.

La pragmàtica de 1302 va implicar una nova ofensiva reial. Com és sabut, s'hi vedava la fe pública als eclesiàstics, reconeixent però les concessions anteriors sempre que la funció no fos exercida personalment $\mathrm{i}$ els clergues es fessin substituir per notaris laics. Les institucions eclesiàstiques no acceptaren sense protestar la supressió d'un dret com el de la notaria, que els proporcionava ingressos i influència. A Piera, on la notaria tenia poders exclusius sobre tot el territori de la batllia i la recentment creada sotsvegueria (termes de Piera, Masquefa, Pierola, Cabrera i Vallbona), sabem que el rei intentà reassignar l'escrivania. El 1319 la Cancelleria reial expedí una concessió vitalícia de les rendes de les escrivanies de les batllies i de les sotsvegueries de Piera i d'Igualada (que només podria fer-se efectiva a la mort del vescomte de Cardona que, pels pactes amb el rei, posseïa totes

\footnotetext{
${ }^{25} \mathrm{ACA}, \mathrm{C}$, reg. 60 , fol. 35 v., abril de 1282. L'any següent actuava amb l'autoritat del batlle de Piera (AHMP, Pergamins, núm. 550, 11-02-1283). La primera acta que coneixem de Guillem Roig (un establiment) a ibid., XVI-2, Sumari dels sensos y delmes que lo monestir reb en lo terme de Piera, 1350, interior de contraportada, 21-07-1263. Hi ha diversos Roig (ms. Rubei) documentats a Piera actuant com a notaris, segurament d'un mateixa família: Bernat Roig, els anys 1235, 1238 i 1239 (vegeu Josep RIUS I SERRA, ed., Cartulario de San Cugat del Vallés, III, Barcelona, 1947, p. 445, § 1329, p. 468, § 1351, pp. 472-73, §1357, pp. 473-75, $\S 1358$, i p. $475, \S 1359$ ); Pere Roig, notari de Piera (AHMP, Pergamins, núm. 562, 20-081289, fins a ibid., núm. 692, 13-07-1329); el seu germà Berenguer Roig, notari públic pel rector l'any 1296 (ACA, C, Pergamins, carp. 143, núm. 729, amb Pere Roig actuant com a escrivà, Guillem Roig fent de testimoni i on s'esmenta també un Arnau, fill d'Arnau Roig; i AHMP, Pergamins, núm. 591, 23-08-1300, on apareix com a germà de Pere; i el 1330 signa actes com a notari substitut del rector - vegeu la nota 20); un altre Berenguer Roig (ibid., núm. 588, 08-11-1353, fins a ibid., núm. 590, 07-02-1385).

${ }^{26} \mathrm{ACA}, \mathrm{C}$, reg. 340, fols. 22 v.-23, 06-05-1296. Sobre el projecte de Ramon de Besalú i les seves conseqüències, vegeu FERRER I MALLOL, L'expansió d'una regalia, pp. 56-58 (on es publica el document), i en particular, CONDE Y DELGADO DE MOLINA, La titularidad de las notarícs.
} 
les rendes dels dits llocs també de per vida) a favor de l'escrivà major del rei Bernat Codony, domiciliat a Cervera, i de Berenguer Conill, de la Casa del rei. A la mort del Cardona, quan provaren de fer efectiva la concessió a Piera, toparen amb l'oposició del rector, que exigí el reconeixement dels seus drets i el rei va haver de revocar les concessions $(1321)^{27}$.

Però Codony i Conill no van conformar-se, i apel-laren. El bisbe intervingué davant el rei, i aquest comissionà el plet al jurista de Vilafranca Guillem Alemany, tot anunciant la revocació provisional de les concessions al batlle i al sotsveguer de Piera $(1322)^{28}$. Quatre anys i mig després Alemany dictà sentència desfavorable al rector Pere de Cardona, aquest tornà a apel-lar i la causa fou comissionada ara al jurista de Barcelona Bartomeu d'Amer (1327). El rei anul-là la presa de possessió de les escrivanies que ja havia estat lliurada pel batlle general i manà al batlle de Piera que les lliurés provisionalment, amb tots els llibres, escriptures i altres pertinences, al rector. Tanmateix, en negar-se aquest a pagar les despeses processals com li corresponia, el batlle va retardar el compliment de l'ordre, el rector respongué amb l'excomunió, i el rei féu costat al batlle ${ }^{29}$. Davant d'això, una nova intervenció del bisbe, ara contravenint obertament la pragmàtica de 1302: al·legant una absència del rector Pere de Cardona, aleshores a la cort papal, nomenà Berenguer Matoses, que era clergue a l'església de Piera, perquè substituís l'escrivà (laic) Pere Roig, que l'exercí en nom del rector $^{30}$. No hem localitzat documentació sobre el final d'aquest enfronta-

\footnotetext{
${ }^{27} \mathrm{La}$ concessió a Codony a ACA, C, reg. 232, fol. 299 v., 12-07-1319. L'ordre de revocació al batlle general de Catalunya, al-legant una badada de la Cort $\mathrm{i}$ esmentant la de Conill. a ibid., reg. 233 . ff. $166 \mathrm{r}$.-v. i $166 \mathrm{v}$. Sobre la notaria d'Igualada, que pertanyia al rector de Santa Maria, vegeu Joan CRUz I Rodríguez, Notaris i escrivans a Igualada: una aproximació a la seva história, a SANS I TRAVÉ (coord.), "Actes del I Congrés", pp. 549-57.

${ }^{28}$ La comissió a ACA, C, reg. 246, fol. 328, 19-01-1322. La revocació provisional a ibid., fol. 328v, 20-01-1322. La intervenció del bisbe es palesa a ibid., f. 327 v., 20-01-1322. Dos mesos més tard, Jaume II tornava a insistir a Guillem Alemany que procedís immediatament $i$ sense dilacions malicioses en aquesta causa (ibid., reg. 247, fol. 15. 22-02-1322).

${ }^{29} \mathrm{La}$ comissió a Bartomeu d'Amer a ACA, C, reg. 188, fols. 189 v.-190, 14-01-1327, on s'anul la l'ordre de presa de possessió a favor de Codony i Conill dictada pel batlle general en donar per exhaurit el termini d'apel lació per part del rector (21-10-1326), després de verificar que aquest l'efectuà davant notari el proppassat primer d'octubre. L'ordre al batlle per congelar el compliment de la carta anterior a ibid., fol. 202, 25-01-1327.

${ }^{30} \mathrm{ADB}$, Communium, reg. 4 (1325-1330), fol. 91 v., 03-05-1327. El bisbe li donava potestat per confegir instruments nupcials, testaments $i$ altres contractes $i$ actes públics, $i$ els relatius a causes $i$ negocis civils $i$ criminals que de costum eren redactats per l'escrivà de la parròquia.
} 
ment, però per les notícies posteriors que tenim intuïm que les parts van romandre enfrontades durant molts anys, amb posicions irreductibles.

En els anys següents tenim notícies de diversos notaris actuant a Piera, aparentment fora del control del rector i pel que sembla emparats en la batllia ${ }^{31}$. En efecte, sabem que Berenguer Conill, a qui el rei havia concedit l'escrivania el 1319, continuava posseint-la el 1347, i que el 1350 la detenia un cert Francesc Calmomina, i no el rector ${ }^{32}$. L'Església, és clar, no s'avingué a aquesta situació i sembla que, davant l'evident il·legalitat de la conculcació del privilegi de 1252 (reforçat per la pragmàtica de 1302 i la seva confirmació de 1328), adoptà una actitud de resistència passiva: quan Guillem de Claramunt, senyor de l'Ordal, es volgué servir en un procés judicial de l'acta de cessió al seu favor feta pel donzell Pere de Castellolí, es trobà amb la impugnació del vicari general del bisbe, al·legant la incapacitat del notari que clogué l'acta, Berenguer Coaner $(1337)^{33}$. Aquest document ens indica quin era el valor per a l'Església, més enllà de l'econòmic, del control de l'escrivania pública. A Valls, on el rector també era titular de la notaria - aquí per delegació de l'arquebisbe de Tarragona, senyor del lloc-, anys enrere (1319), s'havia arribat a un acord amb els síndics de la vila en el qual aquests aconseguiren garanties en l'elaboració dels documents públics, i contra la discriminació per motius religiosos i altres $^{34}$.

\footnotetext{
${ }^{31}$ Berenguer Cotoner (ACA, C, reg. 489, fols. 177 v.-179, 01-09-1335, on s'esmenta el nomenament de síndics fet pel batlle i signat per aquest notari el 16-04-1335); i Guillem Graner (ibid., Pergamins, carp. 235, núm. 48, 30-05-1336, nomenament de procuradors per part del consell de la vila per a una ambaixada al rei, amb el testimoni del sotsdiaca i el vistiplau del lloctinent del batlle).

${ }^{32}$ Per Conill, vegeu ACA, C, Pergamins, carp. 262, núm. 1341, 09-12-1347, nomenament de síndics per representar la vila en corts, amb el vistiplau del batlle rubricat pel regent de l'escrivà de la cort del batlle, Berenguer Roig, substitut designat per Berenguer Conill. El mateix Roig, scriptor regens scribaniam curie dicti baiuli, ara com a substitut de Francesc Calmomina, rubricà el vistiplau del batlle en un document similar tres anys després, amb el subscripció de Ramon Ferrer, notarius publicus Apiarie pro rectore eiusdem ville auctoritate domini regis (ibid., carp. 267, núm. 1566, 26-08-1350).

${ }^{33} \mathrm{ADB}$, Communium, reg. 7 (1336-1338), fol. 141 v.-142, 24-09-1337. El vicari en demana una iñvestigació, recordant que a la vila de Piera i tota la seva parròquia només tenia autoritat per rebre i redactar documents públics el rector o aquell qui, en el seu nom, n'hagués obtingut potestat.

${ }^{34}$ Joan Papell I TARDiu, Aportació documental a la història del notariat a Valls: l'acta de conciliació entre el rector, titular de la notaria, $i$ els síndics de la vila (1319), a Josep M. SANS I TRAVÉ (coord.), "Estudis sobre història de la institució notarial a Catalunya en honor de Raimon Noguera", Barcelona, 1988, pp. 107-13. En el mateix sentit devia anar la concessió efectuada per Alfons el Benigne als jurats $i$ a la universitat de la vila de Piera, per la qual
} 
D'aquesta manera, sembla que s'arribà a una duplicació de funcions en la qual cada part féu valdre les seves pretensions per la via dels fets. Ultra les cessions de l'escrivania efectuades pel rei, els documents reials esmenten notaris a Piera, sovint qualificant-los d'"escrivà de la cort del batlle" ${ }^{135}$, i ni el sobirà ni els altres senyors no renunciaren a fer referència a la notaria en les vendes de la jurisdicció de la vila ${ }^{36}$. Per altra banda, el rector continuà establint-la a un notari de la vila ${ }^{37}$, i el bisbe mai no oblidava d'esmentar l'escrivania adjunta en els seus nomenaments parroquials $^{38}$. Quan a finals del segle XIV Piera pertanyia als comtes d'Urgell,

manava que els contractes signats per forasters a la gent de la vila, que després traslladessin el seu domicili a Piera, tinguessin plena validesa (ACA. C. reg. 483, fol. 271 v.. 24-08-1331)

${ }^{35}$ Fora de les ja esmentades. el 1362 el batlle general establí la notaria de Piera a l'escrivà de la vila Guillem Deslledó (AHMP, Pergamins, núm. 862, 01-05-1362. perdut però regestat a l'Speculum de pergamins del mateix arxiu, XVIII, llibre 2, p. 418).

Quant als notaris, vegeu la demanda d una cònia d’un document fet per Ramon Lluçà, a Jaume Oller. ambdós "notaris de Piera" (ACA, C. reg. 1621, fol. 189 v., 23-04-1372; ibid. reg. 1623. fols. 73 v. -74, 07-05-1372); la demanda de còpies dels títols que tingués l'Orde de Sant Jordi d'Alfama a Piera. a fer pel "notari de la cort del batlle" (ibid., reg. 791, fols. $82 \mathrm{v}$. [esborrany] i 97 v.. 21-10-1376): la demanda similar respecte del monestir de Pedralbes, a fer pel "notari de Piera" (ibid., reg. 789, fols. 72 v.-73, 07-11-1376: i ibid., reg. 793, fol. 25, 1006-1377): la venda de Piera a Esperandéu Cardona, que és ratificada a la vila davant del notari Pere Granyana (vegeu la nota 17); etc. Els capbreus inclouen els manifestos d'alguns notaris; el de 1555, per exemple, inclou la de Joan Teixidor. "notari, escrivà de la cort del batlle", i la de Miquel Ferriol, "notari" (ACA. Fons notarial, dist. d'Igualada, núm. 1043, olim 189; i còpia en millor estat a l'AMP). Hi ha la possibilitat, tot i que no s“indica directament, que aquests notaris actuessin com a substituts del rector.

${ }^{36}$ Per exemple, en la feta a favor de Pedralbes (vegeu la nota 18). També inclou l'escrivania l'acta de venda feta pel comte d'Urgell a Esperandéu Cardona (nota 17).

${ }^{37}$ Vegeu les reduccions de censos de Pedralbes. la majoria de les quals són de 1330, i algunes de 1350 i 1360 , efectuades per Berenguer Roig, notarius publicus Apiarie pro rectore eiusdem ville auctoritate domini regis (AHMP. XVI-1, Capbreu de reduccions de las servituts $\langle$ que > feyan los terratinents del terme de Piera al coment de Pedralbes, còpia de 1378). En els segles següents continuem trobant notaris actuant en nom del rector: aixi actuava. per exemple. el prevere Bernat Pegeni, a principis del segle XVI (ibid., Pergamins, núm. 583, 2905-1506, donació de héns per esponsalici). Cal dir, però. que és possible que alguns sacomodessin a aquesta situació de duplicitat. com es donà, per exemple, a La Garriga; vegeu Josep Maurí i SERRA, De una escribania rural (siglos XIV, XV y'XVI), "EHDAP", II (1950), pp. 297-309

${ }^{38}$ Vegeu, per exemple, el manament a Bernat de Tous. degà de Piera, i a Pere Morató, prevere beneficiat a Piera, perquè, amb la rectoria vacant. escullin un administrador provisional de les rendes de la parròquia, i es facin càrrec d’aquesta, i de l'escrivania i l’hospital que hi són adjunts (ADB, Gratiarum, reg. 1 [1363-1365], fols. 55 v.-56 v., 18-08-1363). O els nomenaments de rector per a la sufragània de Sant Nicolau del Freixe, on sempre s'esmenta l'escrivania adjunta a la capella (ibid., reg. 5 [1372-1373], fol. 30 r.-v., 15-03-1372; etc.) O el requeriment de verificació documental "en els protocols de l'escrivania adjunta a la rectoria" i d'expedició d'una còpia d'un original de 1328 a favor del beneficiat Joan de Claramunt (ibid., fol. 188 r.-v., 11-02-1373). O el nomenament de vicari a favor del beneficiat Bernat Brugal. donant-li potestat per regir "la cura de les ànimes de la parròquia i també l'escrivania adjunta" 
des de la Batllia General s'intentà retenir l'escrivania de la sotsvegueria alhora que es reconeixia la de la batllia al comte ${ }^{39}$. Aquesta mateixa parcel-lació del dret de notaria fou practicada des del bisbat, en reservar-se l'establiment de l'escrivania del deganat ${ }^{40}$. En darrera instància, però, el monarca no podia evitar la vigència del privilegi de 1252 , i sembla que quan la jurisdicció fou alienada la Corona optà per afavorir els drets del rector enfront de les pretensions dels nous senyors: Arnau de Tous, un dels rectors més destacats del període, obtingué de la reina Maria, aleshores lloctinent del seu marit Alfons el Magnànim, que fes renunciar Esperandéu Cardona a l'empara que havia fet de la notaria de la vila i d'altres rendes pertanyents a la parròquia (1420). Aquest document ens proporciona dues dades importants: per una banda, els fruits o censos que donava l'escrivania a l'erari reial, invariables des de 1252 (2 masmodines l'any, equivalents a 20 sous barcelonesos), i, per l'altra, que aquesta renda estava aleshores assignada a l'abadessa de Valldonzella ${ }^{41}$.

Com el Cardona, Pedralbes intentà sempre de fer valdre el dret que li atorgava la carta de venda, i el rector s'hi oposà aferrissadament. Després de la guerra civil, quan el monestir recuperà la plena potestat sobre la vila, establí l'escrivania de la batllia a Joan Mercer (1491), però poc després

(ibid., reg. 17 [1405-1408], fol. 14, 20-01-1406).

${ }^{39}$ El 1390 el batlle general de Catalunya sol-licità un informe al batlle de Piera sobre el valor que poguessin tenir les escrivanies de la sotsvegueria - atribuïda al rei- i de la batllia - del comte d'Urgell (AHMP, XXIII, lligall P, núm. 182, 30-06-1390, còpia de mitjan segle XVIII). Sobre aquesta estratègia de la Corona, vegeu CONDE Y DELGADO DE MOLINA, El pas de l'escrivà al notari, p. 449.

${ }^{40} \mathrm{ADB}$, Communium, reg. 14 (1345-1348), fols. 9 v.-10, 26-11-1345, a favor de Jaume de Garrigues, pagant de cens anual a la mensa episcopal un parell de capons per Nadal; ibid., reg. 15 (1348-1349), fol. 15, 08-08-1348 (regestat per Ricard F. GYUG, The diocese of Barcelona during the Black Death: the register "Notule Communium" 15 [1348-1349], Toronto, 1994, pp. 130-31, §*179), a favor d'Esteve Mateu, administrador de l'hospital de Sant Francesc de Piera; ibid., reg. 40 (1378-1381), fol. 56 v., 30-09-1378, a favor d'Arnau Terrassola, pagant 50 sous per sant Miquel; ibid., Gratiarum, reg. 13 (1391-1399), fol. 244 r.-v., 28-08-1399, a favor de Bernat Canaletes, havent de pagar la meitat dels 50 sous per Nadal i l'altra meitat per sant Joan.

${ }^{41} \mathrm{ACA}, \mathrm{C}$, reg. 3108, fol. 84, 24-07-1420. Entre les assignacions de rendes reials per al manteniment del monestir de Valldonzella, hi ha també 800 sous anuals sobre els censos del mercat de Piera (ibid., reg. 926, ff. 159 v.-160 v., 09-09-1374). D'aquesta època data l'únic manual notarial (un fragment) conservat actualment a l'arxiu parroquial (APP, llibre 1, núm. 2, 15-06-1422 a 21-04-1423). Sobre l'apropiació de la notaria per part dels barons entenent-la com un dels drets derivats de la jurisdicció, vegeu CONDE Y DELGADO DE MOLINA, El pas de l'escrivà al notari, pp. 449-52. 
sabem que hi actuaven notaris en nom del rector ${ }^{42}$. Però seria en el segle XVII, ja lluny del període objecte d'aquest treball, que esclataria el conflicte definitiu, amb plets a la Reial Audiència i a la Batllia General. Finalment, poc abans de la Nova Planta, Pedralbes aconseguí fer-se reconèixer la potestat d'establir l'escrivania de la batllia, mentre que el rector va haver de conformar-se amb validar actes de l'exclusiva esfera del dret privat ${ }^{43}$.

\section{LA CURA D’ÀNIMES I LES SEVES DIFICULTATS A LA PARRÒQUIA DE PIERA}

Però, naturalment, les funcions del rector de Piera no es limitaven al dret de notaria. La "cura de les ànimes" era la seva comesa principal i la seva raó de ser. Com s'exercia aquesta "cura de les ànimes" dels pierencs des de la parròquia? Tot seguit farem una breu exposició de les notícies que en tenim, majoritàriament indirectes.

Les visites pastorals dels bisbes a les parròquies constitueixen una font històrica valuosíssima per multitud de temes, ja que en presenten una autèntica radiografia ${ }^{44}$. Per a Piera, la primera visita conservada és

\footnotetext{
${ }^{42} L$ 'establiment a favor de Mercer, que era un escrivà de Piera, per un cens anual de 5 sous per Nadal, a AHMP, Pergamins, 879E, 25-09-1491, perdut però regestat a I'Speculum de pergamins del mateix arxiu, XVIII, llibre 2, fol. 422 r.-v., on s'indica que també contenia, enrotllat, el memorial d'un plet entre la vila i el monestir. Sobre els notaris del rector, vegeu la nota 37 .

${ }^{43} \mathrm{El} 1632$ el rector obtingué una sentència favorable contra alguns notaris de la vila, però la invasió del dret continuà $i$ el 1693 el rector Rafael Riera decidí cedir la notaria al notari Jeroni Sastre i als seus descendents, reservant-se només la confecció de testaments, cessió que naturalment s'oposava a les pretensions de Pedralbes, que continuà litigant. Arran de la cessió, el notari Sastre pagaria un cens de 18 Iliures (convertides en 15 després d'haver efectuat un dipòsit de 300) al rector, 6 ducats a la Cambra Apostòlica i 2 morabatins al físc reial. Amb el reconeixement dels drets de Pedralbes, Sastre aconseguí que el monestir li establís l'escrivania a perpetuïtat a ell i a la seva descendència, si eren notaris o dones casades amb notaris (ADB, Communium, reg. 90 [1689-1698], fol. 460, 14-11-1693, carta informant el bisbe de la cessió: i, AHMP. XXIII, lligall P-bis, núm. 182. diversos plecs datats entre 06-03-1694 i 05-02-1705). És probable que el darrer establiment de l'escrivania de la cort del batlle de Piera fet pel monestir de Pedralbes fos l'efectuat vitalíciament a favor de Marià Cases i Boldú (ibid., lligall P-Q, núm. 182, 1804). Vegeu Andreu De Palma, Santa Maria de Piera, pp. 128-32.

${ }^{4}$ Sobre les visites pastorals com a font històrica, vegeu entre d’altres els treballs de Noël COULET, Les visites pastorales, Turnhout, 1977; Josep M. MARTi I BONET i Leandre NIQUI 1 PUIGVERT, Els processos de les Visites Pastorals del primer any del pontificat de Ponç de Gualba (a. 1303), al recull d'ells mateixos i Fèlix MIQuel I MASCORT, "Processos de l'Arxiu Diocesà de Barcelona". I, Barcelona, 1984; Pere BENITO I MONCLÚS, Les parròquies del Maresme a la Baixa Edat Mitjana: una aproximació des de les visites pastorals (1305-1446).
} 
l'efectuada pel bisbe Ponç de Gualba l'any 1303. Aquesta visita té una estructura senzilla si la comparem amb les següents. En primer lloc, el bisbe crida tots els tonsurats i els que haguessin rebut ordres menors: se'n presenten 35 (6 d'ells casats), entre els quals hi ha membres de les famílies més destacades (Claramunt, Sescorts, Matoses). Tot seguit, hom passa a ocupar-se de l'estat (moral i espiritual) de la parròquia: es recullen denúncies dels veïns contra els clergues (concubinatge, fills naturals, adquisició de béns per part d'eclesiàstics, usura) i altres veïns (adulteri, abandó de domicili, fills naturals, prostitució). A continuació, es repassa l'estat de comptes dels llegats a favor de la parròquia (capellanies i beneficis) o les institucions adjuntes (hospital de Sant Francesc), i es procedeix a la revisió d'excomunions, si fa al cas. Finalment, es recull el llistat dels que han estat tonsurats pel bisbe durant la visita: 32 individus (1 d'ells menor, de 8 anys), novament amb la presència de membres de les principals famílies ${ }^{45}$.

La visita del bisbe Ferrer d'Abella (1336) resulta molt més interessant. El bisbe s'informa de l'estat de la parròquia amb el testimoni directe de cinc vilatans. Aquests li fan saber que la parròquia no estava ben servida ("dixit primo super servicio ecclesie ipsius quod ipsum officium non fit bene nec complete ut solebat immo cotidie diminuitur tota die et defficitur"), ja que hi caldrien un diaca i dos preveres més - malgrat l'autorització expressa dictada el 1325- perquè tan sols hi ha dos clergues i set o vuit beneficiats, i aquests es limiten a dir les misses que els pertoquen pels seus beneficis. A més a més, li denuncien que no acullen com caldria els predicadors $\mathrm{i}$ altres religiosos forasters ("non tenetur hospitalitas ut deceret et predicatores et alii religiosi male recipiuntur"), perquè el rector

Mataró. 1992: i Mª . Milagros CÁrCel OrTí i José Vicente BoSCÀ Codina, Visitas pastorales de Valencia (siglos XIV-XV). València, 1996

${ }^{45}$ ADB. Visites Pastorals, reg. 1/1, fols. 6-8, publicada per MARTi I BONET i NIQUI I PUIGVERT, Els processos de les Visites Pastorals, pp. 53-55.

L hospital de Sant Francesc fou cedit pel bisbe als Trinitaris a instància dels jurats de la vila (1335), que s'havien compromès a pagar 7 lliures anuals per al manteniment de l'hospitaler (ACA, C. reg. 489, fols. 177 v.-179, 01-09-1335, confirmació reial d'aquesta renda). Més tard, en el segle XIV, Iadministració dels Trinitaris fou suspesa temporalment $\mathrm{i}$ assignada al rector de Pierola. El 1413 disposava de sis llits. Recordem que, fins a principis de l'època moderna, els hospitals no foren més que institucions d'acollida de pobres i pelegrins (hospites), malalts o) no, i constituïren la plasmació pràctica del manament de la caritat cristiana, primer limitat a l'Església i després amb una creixent implicació de la burgesia $i$ de les institucions municipals Els Trinitaris. un orde que advocava per una vida religiosa incardinada en la nova societat urbana, s'havien instal lat a Piera vers 1205-1209, en una casa fora muralles i no es traslladaren dins la vila fins al segle XVI, en què ocuparen els edificis de l'hospital de Sant Francesc (vegeu Andreu de Palma, Santa María de Piera, pp. 40-47). 
i els beneficiats s'apropien sistemàticament de la majoria de les almoines, que sovint no arriben per als altres ("rector et benefficiati, quando caritates fiunt, recipiunt illas et inter se dividunt et, si defficit, defficit pauperibus clericis in ipsa ecclesia comunitatibus et egenis, nam ipse rector et benefficiati primo recipiunt quod dicti clerici conducticii"). Per si fos poc, els testimonis denuncien que alguns beneficiats són negligents en les seves obligacions i que entre el clergat de la regió es dóna algun cas de concubinatge. Tot seguit, són els jurats de la vila els que fan una sèrie de peticions i denúncies al bisbe. Li reiteren la petició d'incrementar la dotació de clergues a la parròquia, perquè en la situació actual "l'ofici no s'ich fa solempnament axí com fer s'ic deu ne hic ere acustumat", i la denúncia de negligència contra els beneficiats. També li reiteren els pocs al licients que es troben "los vicaris qui comenen ho tenen en comanda la dita esgleya", els quals es troben que no els "fasen almoyna ne tenguen hospitalitat en la dita sgleya axí com sa·nrere ere acustumat de fer, ço és a saber, per totstemps solien tenir aquí almoyna sabuda e ara no se'n fa gens", i menys encara "els religiosos pasans per la vila", als quals sovint no els donen "a menjar ne a boure". Els jurats demanen al bisbe que els vicaris no acullin bandejats, que segons quins llegats es lliurin a qui la vila designi perquè així "es meten a profict de vestimens e de sobrepelís e d'altres aparelamens de la dita esgleya", i que es mantingui la tradició de "cantar ·III- dies la setmana a Sent Christòffoll" (capella pròxima a la vila) i d'inluminar los altàs al divinal offici". A continuació, els jurats fan les habituals denúncies d'adulteris entre el veïnat, de concubinatge dels clergues, fills naturals $i$ prostitució, amb la corresponent pena pecuniària imposada pel bisbe. Tot seguit, es denuncien els préstecs usuraris realitzats per cristians. I finalment es fa una petició important al bisbe: que donant-se el cas de molts clergues que tenen deutes i altres causes pendents amb llecs, i que s'escuden en la immunitat eclesiàstica davant dels tribunals civils i s'aprofiten de la llunyania de la cort bisbal de Barcelona, i "per aquestes rahons les gens legues donen $<e>$ contribuexen pus mal a les esgleyes", sol-liciten que es creï la figura d'un degà per a la vila i la sotsvegueria de Piera amb potestat per fer justícia sobre els eclesiàstics ${ }^{46}$.

\footnotetext{
${ }^{46} \mathrm{ADB}$, Visites Pastorals, reg. 4, fols. 10-14 v., 07-06-1336. El bisbe Ponç de Gualba ja havia atorgat llicència al rector Pere de Cardona perquè escollís un o dos clergues que l'assistissin en els serveis de l'església durant dos anys, per tal com el rector no sempre podia residir a Piera (ibid., Communium, reg. 4 [1325-1330], fol. 14, 05-08-1325). La petició de
} 
Aquestes primeres visites insisteixen en la negligència dels beneficiats i dels responsables de les dotacions d'aquests beneficis, i en les estretors econòmiques en què vivia el clergat local d'aquell moment que, a la vegada, eren causa de l'actitud dels beneficiats. Aquesta situació, amb un clergat insuficient, beneficis amb dotacions de misèria i preveres negligents de les obligacions contretes per veure's obligats a cercar altres mitjans de subsistència serà reiteradament denunciada per una i altra banda, i el degà es veurà obligat a adoptar posicions del màxim rigor, especialment amb els llecs responsables de les dotalies ${ }^{47}$. És possible que aquesta mateixa situació contribuís a esperonar el rector a defensar els drets adquirits en la notaria.

Probablement com a conseqüència d'aquesta situació econòmica, la visita de 1366 efectuada pel bisbe Guillem de Torrelles —antic rector de Piera- és la primera que fa alçar inventari detallat de l'església, des dels ornaments i els llibres litúrgics fins a les dotacions dels beneficis, alhora que es pren nota de les mancances. Tot i que aquesta vegada es posà l'accent en el control d'aquests aspectes, hom no s'oblidà de preguntar pel compliment espiritual ("et dixerunt quod bene veniunt ad ecclesiam et confitentur decenter tamen non communicant sicut decet") i moral del veïnat i del clergat, ni de fer les tonsures habituals (15 individus). Aquesta estructura es repeteix en les visites posteriors, que se centraran cada vegada més en els

\footnotetext{
creació d'un deganat fou acceptada, i fou nomenat Romeu Suau, rector de Capellades que, en renunciar, fou succeït el 1345 per Berenguer Marganell, rector de Vilademàger (vegeu ANDREU DE Palma, Santa María de Piera, p. 120; i ADB, Communium, reg. 13 [1345-1348], fol. 65 r.-v., 21-06-1345). Aquest gerens vices officialis Apiarie tenia plena potestat contra els rebels i per dictar sentències d'excomunió $i$ interdictes, $i$ altres censures eclesiàstiques, així com per conèixer les causes civils i matrimonials, $i$ altres que corresponguessin al dret canònic. Per contra del que s'ha afirmat, fins i tot en obres recents, durant el període medieval, els bisbes procuraren sempre proveir el deganat i la rectoria en persones diferents.

${ }^{47} \mathrm{Vegeu}$, per exemple, l'ordre al degà perquè compel-lís per censura eclesiàstica tant clergues com llecs a complir les pies causes pels beneficis, els ciris o les llànties de l'església (ADB, Communium, reg. 14 [1345-1348], f. 141 r.-v., 23-01-1347); o bé comissió episcopal per investigar i castigar els casos de negligències, abusos $\mathrm{i}$ defectes en els beneficiats $\mathrm{i}$ altres preveres de l'església de Piera (ibid., reg. 21 [1358-1360], fols. 42 v.-43, 29-03-1369), entre moltes altres notícies.

Entre les admonicions als llecs, vegeu ADB, Gratiarum, reg. 3 (1368-1370), fols. 34 v.-35, 29-11-1368, sobre l'excomunió de Ponç Sescorts per no dotar el benefici de Sant Antoni; ibid., fol. 157 r.-v., 13-08-1369, sobre l'excomunió de Bernat de Garrigues, jurista, referent al benefici de 15.000 sous instituitt pel seu difunt oncle; ibid., Communium, reg. 38 (1375-1378), fols. 48-49, 31-07-1375, excomunió i compromís de Bernat de Claramunt sobre el benefici de Sant Bartomeu; etc. Per al segle XV es conserva un nombre significatiu de processos contra llecs sobre aquest tema.
} 
aspectes materials ${ }^{48}$. La parròquia de Piera tingué greus dificultats per contribuir a la dècima concedida pel papa a Pere III amb motiu de la guerra de Castella. No tan sols alguns parroquians no pagaven delmes, primícies i altres drets que havien de satisfer a l'església de Piera, sinó que les bandositats que hi havia a la vila $i$, en particular, el pas de mercenaris estrangers (les Companyies Blanques?), que robaren tot el que s'havia reunit i els béns de l'església, obligaren el rector Pere Isern a sol-licitar un ajornament $(1367)^{49}$.

Destaquem, a tall d'exemple de l'actitud dels beneficiats, la despossessió dictada pel bisbe del clericus Pere Boixó de la capella de Sant Cristòfol, situada fora muralles, com a resultat de la visita de 1379. Haventse comprovat la denúncia contra ell segons la qual no hi feia personalment cap ofici ni n'hi feia fer per altres ans de forma pública i patent feia de teixidor a la vila i duia una vida completament laica ("officium textorie publice e palea exerceat in villa antedicta et vitam ducat totaliter laycalem"), el bisbe li llevava la possessió de la dita capella i assignava l'administració provisional de les seves rendes a Pere de Soldevila, prevere beneficiat a l'església de Piera. Aquest document, ultra ser indicador d'un auge de la producció tèxtil a la vila, ens confirma la insuficiència d'algunes rendes eclesiàstiques, sobretot enfront d'altres activitats més lucratives ${ }^{50}$. Els preveres amb beneficis més dotats aprofitaren l'absentisme dels altres,

\footnotetext{
${ }^{48} \mathrm{ADB}$, Visites Pastorals, reg. 5 bis, fols. 102 v.-103 v., 10-10-1366. Vegeu també les visites efectuades pels delegats dels bisbes Pere de Planelles (ibid., reg. 7 , fols. 6-7 v., 03-091378, incompleta en el registre; ibid., fols. 140-141 v., 11-09-1379; i ibid., reg. 8, f. 123, $04-$ 10-1382), Joan Ermengol (ibid., reg. 10, fols. 167-168 v., 02-05-1404), i Pere Garcia (ibid., reg. 22 , fols. 218 v.-219, 11-10-1492).

${ }^{49} \mathrm{La}$ concessió, prèvia investigació, de l'ajornament i l'exposició de les causes a ADB, Communium, reg. 28 (1367-1368), fols. 11 v.-12, 30-03-1367. Les gentes extranee nacionis que fecerunt transitum per partes istas van robar l'església per valor de 2.000 sous. En la visita pastoral de 1404 es diu que les rendes de la parròquia pugen a 3.000 sous. Es faculta per fer monició canònica per al pagament de delmes $\mathrm{i}$ altres drets deguts a la parròquia a ibid., fol. 2 r.-v., 08-04-1367.

L'any 1362 tampoc no havia pogut pagar la totalitat dels 500 sous anuals de cens que cada Nadal havia de satisfer a la Pia Almoina de la catedral (ibid., reg. 23 [1361-1363], fol. 238 v., 14-01-1363, requeriment perquè es paguessin 290 sous endarrerits). Sobre els censos de la Pia Almoina, vegeu Tomàs LóPEZ PIZCUETA, El patrimonio inmobiliario de la Pia Almoina de Barcelona en la primera mitad del siglo XIV. "Analecta Sacra Tarraconensia", 65 (1992), pp. 407-33.

${ }^{50} \mathrm{ADB}$, Gratiarum, reg. 8 (1380-1383), fols. 55 v. $-56,14-12-1380$.
} 
pactant-ne la cessió de fet, i d'aquesta manera també l'afavoriren ${ }^{51}$. La lluita per fer complir l'obligació de residència als preveres beneficiats fou llarga ${ }^{52}$. Aquest absentisme arribà a afectar fins i tot els mateixos rectors de Santa Maria, tal com denunciaren els parroquians en la visita de 1382. I si aquest problema afectà la rectoria de Piera, la provisió de rector per a les sufragànies de Sant Nicolau del Freixe i Sant Jaume Sesoliveres encara fou més complicada, ja que molts dels nomenats - habitualment preveres de Piera- hi renunciaven abans d'acabar el termini d'un any pel qual hi eren destinats $^{53}$.

Hem constatat la presència habitual de predicadors itinerants ("religiosos pasans"), que sovint competien per les almoines amb el clergat local $^{54}$. No sabem si a l'època baixmedieval s'observava el costum que més tard és qualificat de "tradicional" de contractar un predicador de Quaresma,

\footnotetext{
${ }^{51}$ Els vicaris generals del bisbat ordenaren al degà de Piera, a instància dels preveres més pobres, que obrís una investigació sobre l'absentisme d'alguns beneficiats de beneficis les rendes de molts dels quals no anaven més enllà de 50 miserables sous anuals i que pactaven amb els beneficiats de beneficis més ben dotats (alguns amb fins a 10 lliures anuals) que hi celebressin per ells, els quals també acumulaven censals morts i altre patrimoni (ADB, Gratiarum, reg. 10 [1386-1387], fol. 14 r.-v., 16-04-1386). Els preveres de Piera també foren acusats d'abusos en la distribució dels diners dels aniversaris de les misses, que aparentment desviaven cap a finalitats profanes, $\mathrm{i}$ el bisbe ordenà al rector que els hi fes retornar sota pena d'una multa de 100 sous, i que a partir d'aleshores s'informés per tot el poble a so de timbals de les dates de les misses dels aniversaris (ibid., reg. 14, [1399-1401], fols. 66 v.-67, 14-01-1400). El 1379 el bisbe manà al rector que nomenés un nou prevere procurador per a la collecta i distribució dels aniversaris i almoines per un any, i que presentés comptes en acabar la seva gestió; feia quinze anys que els preveres procuradors no presentaven comptes i sembla que havien retingut certes quantitats (ibid., Communium, reg. 39 [1375-1383], fols. 115-116 v., 10-01-1379).

${ }^{52}$ Ultra els altres documents citats, vegeu l'ordre del bisbe Joan Ermengol al degà perquè fes tornar tots els beneficiats absents sense llicència especial al compliment de les seves obligacions o que els segrestés totes les rendes (ADB, Gratiarum, reg. 14 [1399-1401], fol. 90 v., 07-05-1400). Una nova ordre personalitzada en diversos preveres a ibid., Gratiarum, reg. 22 (1414-1416), fol. 157, 27-01-1416

${ }^{53} \mathrm{Per}$ a l'absentisme dels rectors pierencs, vegeu el rectorologi i les notes 46 i 48 . Per a les sufragànies, vegeu, entre molts altres documents, ADB, Gratiarum, reg. 13 (1391-1399), fol. 8, 03-03-1396, on s'afirma que la primera era vacant des de feia temps; ibid., Visites Pastorals, reg. 10, fols. 167-168 v., 02-05-1404, on s'explica la situació d'aquella mateixa; o ibid., Gratiarum, reg. 25 (1421-1422), fols. 161 v.-162, 04-08-1422, on es nomena un administrador provisional de les rendes de la segona, confiscades al rector absentista Joan de Mengua.

${ }^{54}$ Sobre la predicació medieval, vegeu en general els treballs reunits a Thomas L. AMOS et al. (eds.), De ore domini: preacher and word in the Middle Ages, Kalamazoo, 1989; i Jacqueline HAMESSE i Xavier HERMAND (eds.), De l'homélie au sermon: histoire de la prédication médiévale. Actes du colloque international de Louvain-la-Neuve, 9-11 juillet 1992, Louvain-la-Neuve, 1993. Sobre l'ús de la llengua vulgar en la predicació, vegeu Vittorio COLETTI, Parole dal pulpito, Casale Monferrato, 1983. Sobre predicació i minories, vegeu David Nirenberg, Communities of violence: persecution of minorities in the Middle Ages, Princeton, 1996.
} 
efectuant-ne la selecció conjuntament entre la comunitat de preveres i els jurats de la vila ${ }^{55}$. Aquests predicadors sovint eren responsables d'instigar la gent a la violència i les autoritats locals a la discriminació contra les minories, en especial contra els jueus, en els seus sermons de la Setmana Santa. El 1330 la petita comunitat jueva de Piera exposà al rei que alguns dels habitants de la vila els molestaven i els apedregaven quan ells entraven o sortien de la població, els seus deutors feien l'orni a l'hora de tornar-los els préstecs, i els jurats de la vila havien arribat a dictar una ordinació prohibint-los de comprar carn en les taules de carnisseria cristianes $i$ obligant-los a col-locar un ninot infamant vestit amb la indumentària que eren forçats a dur en la taula dels jueus. Les ordres taxatives d'Alfons el Benigne al batlle perquè posés ordre i fes revocar l'ordinació no impediren un assalt al call tres anys més tard, justament l'any de caresties conegut com "lo mal any primer" $(1333)^{56}$.

\section{L'ESCOLA PARROQUiAL I LA DE GRAMÀTICA}

El cercle dibuixat pel control espiritual, moral i ideològic, i pel domini de la fe pública, es tancava i trobava la perpetuació en l'educació dels joves cristians a l'escola parroquial. Hem de dir, tanmateix, que durant el període que ens ocupa aquesta no és l'única escola que hem documentat a Piera. Efectivament, com veurem tot seguit, a banda de l'escola parroquial funcionava una escola de gramàtica, i les relacions entre una i altra no van ser sempre fluïdes.

L'origen de les escoles parroquials, com a desenvolupament de les escoles presbiterals creades en el segle VI sovint en els llocs situats en vies de comunicació importants on, en alguns casos, ja hi havia hagut una escola romana, ha estat ben estudiat ${ }^{57}$. A Piera, tot $i$ que no l'hem vist esmentada

\footnotetext{
${ }^{55}$ Els anys 1775-1776 esclatà un conflicte entre la comunitat de preveres i l'ajuntament, en intentar forçar aquest sense èxit la contractació d'un predicador de la seva preferència oferint-li més diners (vegeu APP. caixa 3, núm. 8, 03-11-1775, i ibid, caixa 1, núm. 51, 16-02-1776).

${ }^{56} \mathrm{ACA}, \mathrm{C}$, reg. 438, fol. 225 r.-v., 11-05-1330, i ibid., reg. 457, fol. 224 v., 21-03-1333. recollits i comentats per NIRENBERG. Communities of violence, pp. 171 i 204.

${ }^{57}$ Vegeu Pierre RICHÉ, Éducation et culture dans l'Occident barbare (VI'-VIII' siècles). París. 1962 [reed. revisada: París. 1972]. pp. 324-28 i 510-20; i d'ell mateix. Écoles et enseignement dans le Haut Moven Agge (fin du V" siècle-milieu du XI' siècle). París. 1979 |reed. revisada: París. 1989]. pp. 192-93. Les notícies que s’hi dónen sobre la península Ibèrica, poden
} 
explícitament en les visites pastorals, no sabem si aquesta escola es trobava situada en els mateixos edificis parroquials. El que sí és cert és que els bisbes se n'ocuparen assíduament, encara que no podem confirmar el panorama descrit per Riché en la França altomedieval, on el mestre presentava els estudiants al bisbe durant la visita pastoral i aquest els feia preguntes sobre el que havien après, especialment en matèria sagrada ${ }^{58}$. Això ens indica l'interès dels bisbes per encoratjar les vocacions que, a Piera, veiem clar en les tonsures efectuades a alguns scholares o "escolans" durant les visites o bé en altres ocasions. Els trenta-dos tonsurats durant la visita de Piera de 1303 no se'ns indica que fossin estudiants; és probable que no tots ho fossin, però sabem que un d'ells només tenia vuit anys. En canvi, en la visita de 1366 sí que se'ns explicita que els quinze tonsurats eren estudiants: "qua visitacione facta per dictus reverendus dominus episcopus, predicta die dominica decima die octobris, in dicta ecclesia parrochiali Sancte Marie ville de Apiaria, infrascriptos scolares in clericos tonsuravit". Segueix la llista d'aquests scholares, gairebé tots ells de Piera, aquest cop especificant les seves filiacions. En una i altra llista podem observar la presència de membres de les famílies principals (Claramunt, Sescorts, Matoses), alhora que hi reconeixem dos fills de notaris al costat de molts altres que ho eren de pagesos benestants. Per altra banda, podem constatar l'assistència a l'escola parroquial de Piera (almenys a principis del segle XIV) d'estudiants procedents d'altres localitats de la regió que potser no en disposaven $^{59}$. Aquestes escoles solien estar regentades per un sol mestre,

completar-se amb el treball d'Antonio García García, Vocabulario de las escuelas en la Península Ibérica, a Olga WeIJERS (ed.), "Vocabulaire des écoles et des méthodes d'enseignement au Moyen Âge: Actes du colloque de Rome (21-22 octobre 1989)", Turnhout, 1992, pp. $157-78$.

${ }^{58} \mathrm{R}$ ICHÉ, Éducation, p. 326. Els mestres també els feien exàmens escrits.

${ }^{59} \mathrm{El} 1303$ foren tonsurats: Jaume de Claramunt, Bernat Cortall, Guillem Baster, Guillem Sales, Berenguer Gorg, Ramon Sespunyades, Ramon Elies, Arnau Eralló (ms. "Arayó"), Guillem Marbres, Pere Ferrer, Ramon Orpí, Bartomeu Froc, Bartomeu Pic, Bernat Sespunyades, Bonanat Baster, Guillem Claramunt, Bernat Droc, Pericó Claramunt, Pere Rossell, Berenguer Ventosa, Pere Sort, Berenguer Canaletes, Berenguer Joan, Francesc Merola, Jaume de Garrigues, Berenguer Parent (d'Olesa de Montserrat), Guillem de Croses (de Sant Climent), Pere de Valls, Robert Alegre, Guillem Vilanova, Guerau de Casalroig (de Sant Jaume Sesoliveres) i Francesc Vidal (de vuit anys). Els tonsurats de 1366 foren: Arnau Terrassola, fill d'Arnau Terrassola, Antoni Oliver, fill de Berenguer Oliver $(\dagger)$, Berenguer Claret, fill de Berenguer Claret $(\dagger)$, Ramon Torelló (ms. "Toroyó"), fill de Pere Torelló, Berenguer Cortall (més tard prev. beneficiat), fill de Guillem Cortall (administrador), Pere Argençola (més tard prev. beneficiat), fill de Ramon Argençola, Berenguer Perpinyà, fïll de Berenguer Perpinyà, Berenguer Guerau, fill de Berenguer Guerau, Miquel Julià, fill de Bernat Julià, Pere de 
que era un dels preveres de la comunitat - tot i que en el cas de Piera no n'hem pogut identificar cap com a mestre.

$\mathrm{Si}$ en un principi eren escoles adreçades preferentment a la preparació dels clergues inferiors que ajudaven el rector i, més en general, a la formació elemental dels qui entrarien en la carrera eclesiàstica, aviat van obrir-se també als joves llecs cristians de la parròquia ${ }^{60}$. Aparentment, l'ensenyament donat en aquestes escoles era gratuït (però els estudiants, sovint interns, havien de mantenir-se pels seus propis mitjans) i quedava en mans dels rectors instar per monicions els parroquians a dur els infants a l'escola. En les escoles parroquials els infants aprenien a llegir i a escriure, els rudiments de la doctrina cristiana i també nocions de cant, d'història (sagrada) i d'aritmètica en el seu aspecte més elemental i pràctic (càlcul amb l'àbac). Un cop havien après a lletrejar, els escolars començaven a llegir els salms, possiblement cantant-los i rebent alhora algunes nocions de música, i tot seguit estudiaven els textos hagiogràfics ${ }^{61}$. Aquest programa d'estudis podia topar amb una greu dificultat: l'escassa formació del clergat rural durant tota l'Edat Mitjana. Els bisbes intentaren lluitar contra aquest greu problema, en ocasions contra els desitjos dels senyors feudals. Els llibres que hi havia a les esglésies ens poden donar una idea del nivell de cultura dels clergues i de llur capacitat per ensenyar. Certament, a l'església de Piera,

\footnotetext{
Soldevila (més tard prev. beneficiat), fill de Bernat de Soldevila, Bernat Roig, fill de Berenguer Roig (notari), Esteve Aragonès, fill de Romeu Aragonès (de Vallbona), Arnau Ferrer, fill de Ramon Ferrer, notari $(\dagger)$, Ramon Savall, fill de Guillem Savall, i Berenguer Rossell, fill de Berenguer Rossell, àlias Bou. Vegeu les notes 45 i 48. Recordem que durant la visita de 1303 el bisbe cità també els que havien estat tonsurats d'abans o que ja havien rebut ordres (35), només alguns dels quals estaven casats (6); en les visites posteriors el bisbe també comença entrevistant-se amb aquests clergues. Tenim documentats altres casos de tonsures d'estudiants de Piera efectuades pel bisbe Ponç de Gualba a la catedral de Barcelona (ADB, Visites Pastorals, vol. 1/2, fol. 2, 06-04-1303, dos de Piera, tres de Ribes i altres d'Esplugues, Reixac, Subirats i Barcelona) i durant una visita pastoral a Sant Quintí de Mediona (ibid., fol. 31, 1303-1305, diversos de Piera - Pericó de Bages-, Foix, Masquefa, Sant Pere de Riudebitlles, Sant Quintí i Lavern, jurant que volien accedir als ordes sagrats).

${ }^{60}$ RICHÉ, Éducation, p. 325

${ }^{61}$ Ibid., pp. 326 i 513 i ss.
} 
el panorama no era molt encoratjador ${ }^{62}$. Una altra dificultat podia venir donada per la competència amb una altra escola: l'escola de gramàtica.

Efectivament, els documents que tenim per a Piera, ens parlen també de l'existència d'una escola de gramàtica i lògica. En aquestes escoles, a Catalunya fundades de resultes de les disposicions del concili provincial de Lleida de 1229, tot i que l'ensenyament també solia iniciar-se a partir del seu grau més elemental, es feia un pas més en la formació dels estudiants cristians, ja que hi aprenien la llengua sàvia, el llatí (la gramàtica llatina), i les altres arts liberals que constituien el trivium (la lògica i segurament també la retòrica), preparació —amb el quadrivium- per als estudis de filosofia i teologia. No és aquest el lloc per estendre'ns sobre aquestes escoles i l'ensenyament primari i secundari, tema en el qual, tot i que encara no disposem d'una síntesi per al conjunt del nostre país, s'han fet contribu-

\footnotetext{
${ }^{62}$ Sabem que Jaume II donà un oficier, un responser, un leccionari santoral $\mathrm{i}$ un altre de dominical, un evangeliari i un missal a l'església de Piera (ACA, C, reg. 216, fol. 21 v.. 23-051318). Tanmateix, en la visita de 1366 hom trobà a faltar un leccionari dominical i ferial a l'altar major i un missal al de Santa Llúcia, mentre que el de Sant Miquel disposava d'un missal. Durant la visita de 1378 el delegat del bisbe "accessit ad locum in quo libri dicte ecclesie existunt et multum defectum librorum invenit excepto quod est fiendum legendarium divinale et feriale": no obstant això, l'altar de Sant Miquel continuava tenint un misal "satis competens". però no el de Sant Bartomeu ni el del Corpus Christi, i en canvi el de Santa Llúcia ara tenia "unum missale valde parvum et misserimum in quo non potest fieri officium nisi defunctorum". El leccioner continuava mancant el 1379, així que el vicari general del bisbe "injunxit parrochianis quod festo Omnium Sanctorum proxime instantis ad duos annos proxime sequentes habeant unum legenderium dominicale". Però el 1382 es continuava trobant a faltar el leccionari i es posà un nou termini de dos anys per a fer-lo fer. Sembla que el 1404 encara no s'havia fet, i es trobà a faltar també un saltiri (aquell any l'altar major no tenia ni vestidures ni calze). Laaltar de Sant Miquel tenia missal i sagramental i el de Santa Eulalia, missal, però els de Sant Bartomeu. Santa Anna. Sant Antoni i Sant Joan no tenien missal i se"ls imposa un termini d'un any per fer tots els llibres que mancaven. També es trobà a faltar un breviari a Sant Jaume Sesoliveres, que encara fou objecte d'un nou termini el 1418 (ADB, Gratiarum, reg. 23 [1416-1418], fol. 217 v., 10-11-1418). Sobre la cultura dels clergues medievals, vegeu Vicenta BELTRÁN DE HEREDIA, La formación intelectual del clero en España durante los siglos XII, XIII y XIV. "Revista Española de Teología", 6 (1946), pp. 313-357: Ana ArRanz GuZmán. La cultura en el bajo clero: ana primera aproximación. "Anuario de Estudios Medievales", 21 (1991). pp. 591-605; Josep A. IGLESIAS I FONSECA, La cultura dels clergues a la Catalumya baix-mediev'al a trav'és de les seves biblioteques, "Analecta Sacra Tarraconensia", 67 (1993), pp. 93-103; i José M ${ }^{a}$ SOTO RÁBANOS, Disposiciones sobre la cultura del clero parroquial en la literatura destinada a la cura de almas (siglos XIII-XV), "Anuario de Estudios Medievales", 23 (1993), pp. 257-356. Sobre inventaris parroquials, vegeu Lluís BATLLE I PRATS, Noticies de llibres d'antics inventaris de clerecia parroquial del bisbat de Girona, "Anales del Instituto de Estudios Gerundenses", 19 (1968-1969), pp. 231-46; Jocelyn N. HILLGaRTH. Readers and books in Majorca (1229-1550), París, 1991, I. pp. 32-33; i Miri RuBIn, Corpus Christi: the Eucharist in the late medieval culture, Cambridge, 1997, pp. 35-63 i 83-97.
} 
cions importants ${ }^{63}$. Hem de tenir en compte que aquestes escoles, tot i que sorgeixen i ben sovint es mantenen sota el paraigua de l'Església, palesen el procés de laïcització de la vida, amb l'aparició de nous grups socials (burgesia) amb interessos en el món del comerç, el dret o la medicina ${ }^{6 t}$.

El primer document que hem localitzat sobre l'existència d'unes scolas gramatice et logice a Piera data de 1333. En aquell moment n'era "regent" (mestre) el batxiller en arts Pere Gestar. Aquest va aconseguir del bisbe de Barcelona, del qual depenia l'escola, que el costum dels "escolans" de Piera de distribuir (spargere) l'aigua beneïda per les parròquies de la comarca fos reservat a partir de llavors als estudiants pobres per així facilitar-los el seu manteniment. A instància del bisbe, Sanç de Caudarasa, regent de les escoles de la catedral $\mathrm{i}$, com a tal, de les escoles de gramàtica de la diòcesi de Barcelona, va disposar que les esglésies que pertocarien als

\footnotetext{
6.'Lynn ThORNDIKE, Elementany and secondany education in the Middle Ages, "Speculum", 15 (1940): 400-08, ja defensà l'existència d'una educació "secundària" a leèpoca medieval. Sobre l'ensenyament primari i secundari, fonamentalment a Barcelona, vegeu Antonio DE LA TORRE Y DEL CERRO, Documentos para la historia de la Universidad de Barcelona, I (Preliminares, 1289-145I). amb introducció, notes i comentaris de Jordi RUBIÓ I BALAGUER. en part. les pp. 26*-49*: i Josep HeRnANDo I Delgado, L'ensenvament a Barcelona, segle XIV: doctuments dels protocols notarials. "Arxiu de Textos Catalans Antics", 12 (1993), pp. 141-271, i 16 (1997). pp. 131-298. Per als estudis a Igualada, vegeu la capdavantera aportació de Joan SEgura I Valls a la seva Història d'Igualada. II, Barcelona, 1908 /reimpr. facs.: Igualada, 1978|. pp. 63-77. Per a Cervera, vegeu Agustí DuRAN I SANPERE i Frederic GómEZ - Gabernet, Las Escuelas de Gramática en Cervera, "BRABLB", 17 (1944), pp. 5-77 Ireelaborat però sense els documents a l'obra del primer, Llibre de Cervera, Barcelona, 1972 (reimpr. 1977), pp. 283-99]: i Amadeu-J. SOBERANAS I LLEÓ. Una companyia per regir les escoles de gramática i logica de Cervera el curs 1440-1441, "BRABLB", 37 (1977-1978), pp. 167-75. Per a Reus, vegeu Salvador VILASECA I ANGUERA, La tradició escolar a Reus "Aules". 15-16 (1935). Per a Tarragona, vegeu Sanç CAPDEvila I FeliP, Les antigues institucions escolars de la Tarragona restaurada, "Estudis Universitaris Catalans". 12 (1927). pp. 68-162. i 13 (1928). pp. 13-92 [tiratge a part: Barcelona, 1929]: i Francesc CORTIELLA i ODENA. Una ciutat catalana a darreries de la Baixa Edat Mitjana: Tarragona. Tarragona. 1984. pp. 289-314. Per a Girona. vegeu Lluís BATLLE I PRATS, La cultura a Girona de l'Edal Mitjana al Renaivement. Girona, 1979. pp. 281-309. Per a Lleida, vegeu Josep LLADONOSA 1 PUjOL. Historia de Lleida. I. Tàrrega, 1972, pp. 625-26, i d'ell mateix Escoles i mestres antics de minyons a Lleida. Barcelona. 1970. Per a Castelló, vegeu Lluís Revest I CORzo, La enseñanza en Castellón de 1374 a 1400. Castelló de la Plana. 1930. Per a Morella, vegeu Josep ALANYÁ I RoIG. Els estudis medievals de Morella. "Butlleti d'Amics de Morella i Comarca". en premsa. Per a València. Josep SANCHIS I Sivera. La enseñanza en Valencia en la época forcl. "Boletín de la Real Academia de la Historia", 108 (1936): 147-79; José Ma CRUSELLES GÓmEz. Masstros, escuelas urbanas y clientela en la ciudad de Valencia a finales de la Edad Media. "Estudis", 15 (1984), pp. 9-44; IDEM. Los estudiantes de la Valencia preuniversitaria. entre la carrera eclesiastica y la sociedad civil. "Estudis", 23 (1997), pp. 11-40: i IDEM. Escuelas y sociedad en la Valencia bajomedieval. València, 1997. Sobre el programa docent d'aquestes escoles, vegeu particularment l'exposició del cas de Cervera (pp. 290-93).

${ }^{n}$ DE LA TORRE i RUBiÓ, Documentos para la historia. pp. 32-33.
} 
estudiants pobres de Piera per a repartir-hi l'aigua beneïda serien les de Piera, Vallbona, Cabrera, Capellades, la Torre de Claramunt, la Pobla de Claramunt, Vilanova del Camí, Monistrol d'Anoia, Abrera, Sant Llorenç d'Hortons, Sant Jaume Sesoliveres, Sant Nicolau del Freixe, Santa Creu de Creixà i Pierola, pobles que probablement corresponien a l'àrea d'influència de l'escola de Piera ${ }^{65}$. En les escoles de gramàtica els estudiants pobres tenien l'ensenyament gratuït (vegeu el cas de Cervera) i els rics havien de pagar segons el seu nivell i si eren o no interns (vegeu el d'Igualada). Però, com en les parroquials, s'havien de mantenir pels seus propis mitjans.

Per aquells anys, a Piera es plantejà un greu conflicte de competència entre l'escola parroquial i la de gramàtica. Ja hem dit que les escoles parroquials, tot i estar concebudes per a la formació del clergat local, admetien també estudiants llecs que desitjaven adquirir-hi una formació elemental. També hem comentat com les escoles de gramàtica van néixer sota el paraigua episcopal en els nuclis de població més expansius de cada diòcesi. Els governs municipals no tardaren en manifestar interès en influir i controlar aquests centres educatius adreçats primordialment als cadets de la burgesia dominant. Influència i control que, ben sovint, es basaren en el manteniment del mestre per part de la hisenda municipal. Si el primer fet l'hem d'interpretar com una pervivència d'un temps en què no hi havia altres possibilitats de formació i alhora com una de les vies de penetració social de l'Església, el segon ens parla clarament d'una societat en procés de laïcització que busca els intruments formatius més adequats a les noves necessitats i de l'adaptació de l'Església a aquests nous temps. A Piera, l'admissió d'estudiants llecs a l'escola parroquial i de futurs clergues a l'escola de gramàtica conduí a un conflicte que hom intentà de solucionar amb un pacte que delimitava clarament l'àrea social d'influència de cada escola. Aquest pacte fou establert entre Ramon d'Avinyó, prevere regent de la parròquia, i — ben significativament - els jurats i prohoms de la vila, decidint "quod magister scolares ecclesie nisi tamen scolares psalmistas et cantores, et magister scolarum gramatice ipsius ville nisi tamen gramaticos et logicos in suis scolis reciperent et docerent". Però la realitat aviat convertí aquest acord en no res, i hom féu perquè el bisbe requerís, amb censura eclesiàstica, els mestres d'una i altra escola perquè respectessin l'acord i es

\footnotetext{
${ }^{65} \mathrm{ADB}$, Communium, reg. 5 (1330-1334), fol. 206 r.-v., 20-11-1333. Sobre Sanç de Caudarasa, vegeu DE LA TORRE i RUBIÓ, Documentos para la historia, pp. 23-25 i 29-30.
} 
limitessin a rebre i ensenyar els escolars que els corresponien (1334). Aquest important document encara ens aporta una altra notícia de gran interès: es donava a Piera almenys un cas d'un mestre -Guillem Gisbert, clergue de la vila - que oferia ensenyament tant a salmistes com a gramàtics fora de l'estructura de les escoles esmentades ("docet in dicta villa psalmos et gramaticam in dictorum magistrorum preiudicium et prefate ecclesie lesionem, et contra convencionem predictam") i, aparentment, amb un cert suport del municipi. El bisbe manà de fer-lo cessar en el seu ensenyament i amonestà els jurats de la vila perquè no continuessin sostenint-lo a ell ni a altres docents ("ut ipsum Guillelmum et alios eciam inibi volentes docere sciencias supradictas ut ab hiis cessent penitus et desistent, monicione premissa per censuram ecclesiasticam compellatis quam faciatis contra eos inviolabiliter observari, admonentes ulterius juratos dicte ville ex parte nostra quod non sustineant ipsum Guillelmum Gisberti vel aliis ubi docentes dictas sciencias quod predictos nec eis prestent in hoc consilium, auxilium vel favorem"). Efectivament, no era estrany - sobretot a les grans ciutats- que personatges com aquest, molt probablement antics alumnes de les escoles, oferissin ensenyament lliure $\mathrm{i}$ fins $\mathrm{i}$ tot particular. Si bé en ciutats com Barcelona aquest procés fou creixent $\mathrm{i}$ imparable, aquí veiem com en nuclis menors l'Església féu tot el possible per mantenir el seu monopoli sobre l'ensenyament ${ }^{66}$. El pes d'aquest monopoli faria marxar de Piera els qui desitjaven viure de l'ensenyament. En tenim un possible cas en Bernat Bartomeu, fill de Guillem Bartomeu, de Sant Jaume Sesoliveres, i que hom

\footnotetext{
${ }^{66} \mathrm{ADB}$, Communium, reg. 5 (1330-1334), fols. 221 v.-222 v., 18-01-1334. El programa d'estudis de l'escola parroquial de Valls també fou regulat en l'acta de conciliació de 1319 entre el rector i els síndics de la vila: "Item in articulo vel capitulo de pueris seu scolaris adiscentibus et cetera, de minori manu illos intelligi volumus qui adiscunt abecedarium, psalmos et psalterium. De mediocri vero illos que adiscunt epistolas ac etiam lectiones. De maiori, autem. manu cantum seu musicam adiscentes" (PAPELL I TARDIU, Aportació, pp. 110 i 112). A Igualada, el mestre de les escoles de gramàtica i loggica fou nomenat pels síndics l'any 1341, i pagat per aquests a partir de 1346; el 1347, i després d'un conflicte, el municipi pagà un cens de 30 sous al rector per les escoles de la vila (SEGURA I VALLS, Història d'Igualada, II, pp. 63-64)

Un Guillem Gisbert o Girbert era un dels procuradors dels homes de Piera que havien aconseguit defensar el seu dret a no fer prestacions en treball a Saurina, vidua de Guillem Batlle, a Guillem Sescorts $i$ a altres de la vila segons sentència del jurista de Piera Ramon Coaner (ACA, C, reg. 175, fol. 30, 29-04-1322; ibid., fols. 178 v.-179, 19-06-1322; ibid., fol 179 r.-v., mateixa data; ibid., fol. 294 r.-v., 31-07-1322; ibid., reg. 188, fol. 268 r.-v., 26-021327; i ibid., reg. 191, fol. 42 r.-v., 17-08-1327). També figura un clergue d'aquest nom entre els cridats pel bisbe en la visita de 1366 (vegeu la nota 48)
} 
ha pogut documentar entre $1425-1439$ com a magister scolarium oferint els seus serveis privats a Barcelona ${ }^{67}$.

Malauradament, no és fins al segle XVIII que tornem a tenir notícies de les escoles de Piera, i és novament per un conflicte entre la comunitat de preveres i el municipi enfrontats pel nomenament del mestre de primeres lletres i gramàtica. No sabem si el municipi pagava el mestre a finals de l'Edat Mitjana, però a mitjan del Set-cents sí que ho feia, i tenia una part de les rendes de la vila assignades al seu manteniment. No ens hem d'estranyar que el municipi també desitgés tenir veu i vot en la seva seleccióo ${ }^{68}$.

Acabada la formació primària i secundària a les escoles de la vila, els pierencs podien seguir estudis superiors, normalment a Barcelona o a Lleida. Coneixem casos de diversos estudiants pierencs que sortiren de la vila per aconseguir els graus: Ramon i Ombert Coaner, Romeu i Albert Sescorts, tots ells juristes de Piera documentats en els anys vint, trenta i quaranta del segle XIV; Bernat de Garrigues, un altre jurista de Piera, que féu de testimoni en una acta que regulà els exàmens a l'Estudi General de Lleida (1352) i al qui Pere III encomanà la resolució de diversos afers relacionats amb la vila; Arnau de Tous, beneficiat de l'altar de Sant Miquel, absent per raó d'estudis (scolaris) durant les visites pastorals de 1378 i 1379, i després rector; Ramon Torelló, beneficiat de l'altar de Sant Joan i absent per la mateixa raó (studet) durant la visita de 1379; Bernat Sescorts, beneficiat de l'altar de Santa Eulàlia i estudiant dret civil durant la visita de 1404; o Pere Joan Matoses, beneficiat de l'església de Santa Maria del Mar de Barcelona, mestre en arts i corrector de llibres gramaticals $(\dagger 1511)^{69}$.

\footnotetext{
${ }^{67}$ Vegreu DE LA TORRE i RUBió, Documentos para la història, pp. 184-85, 193 i 212-15, on es documenta la filiació i la descendencia a Barcelona: i ACA. RP, MR, vol. 1566, on consta una multa a Guillem Bartomeu per haver mort una ovella de Francesc Mestre en els comptes del sotsveguer de 1362.

${ }^{68} \mathrm{~L}$ 'enfrontament entre la parròquia i la universitat a APP. llibre 1, núm. 11, 1755. En el mateix arxiu (caixa 1, núm. 58) es conserva un certificat de Pau Cases i Alivau, notari i escrivà de la vila de Piera, del que de "propios y arbitrios" produïren, entre 1762 i 1766, la carnisseria, el forn de pa, "la tienda, la ceba por menor y pallol", looli, el fem dels corrals, la fira de Sant Domènec, la fira de Sant Miquel, els censos redimibles i altres censos i censals consignats per particulars i percebuts pel comú en ajuda del mestre.

${ }^{69}$ Sobre Ramon Coaner, vegeu la nota 66 i ACA, C, reg. 428, fol. 126, 05-01-1328. Sobre Ombert Coaner, vegeu ADB, Communium, reg. 14 (1345-1348), f. 110, 30-08-1346. Sobre Romeu i Albert Sescorts, vegeu ACA, C, reg. 489, fols. 177 v.-179, 01-09-1335; i ibid., reg. 861, fols. 176 v.-177, 10-03-1337. Sobre Garrigues, vegeu Antoni RUBIÓ I LLUCH, Documents per l'historia de la cultura catalana mig-ev'al, I, Barcelona, 1908, pp. 160-63, \$ CLXI; i ACA, C, CRD de Pere III, caixa 50, núm. 6149, 18-09-1360, ibid., reg. 790, fol. 186, 22-04-1377, i nota 47. Sobre Tous, Torelló i Sescorts, vegeu les visites pastorals corresponents (nota 48);
} 
Hem vist com al llarg de la Baixa Edat Mitjana, en una societat marcada pel sorgiment de la burgesia, l'església de Piera menà una llarga pugna per mantenir una posició heretada dels segles anteriors que li permetia exercir el seu ministeri en unes condicions privilegiades, tot monopolitzant els àmbits espiritual, educacional i notarial. La nova estructura social l'obligà a un esforç d'adaptació en tots tres àmbits, més visible en els dos darrers. El dret de notaria no únicament proporcionava ingressos a la parròquia, sinó també una considerable influència en tot el territori de la sotsvegueria, mercès al control sobre el notari al qual s'arrendava el dret, sobre els individus als quals es feia l'acta pública, i sobre els documents mateixos, tant en la seva forma com en la seva conservació. La recuperació dels poders públics i la concurrència de jurisdiccions obligà a pactar l'exercici del dret de notaria i a la seva defensa sistemàtica. El domini de la fe pública complementava les tasques de "cura de les ànimes", dutes a terme per la rectoria i la comunitat de preveres malgrat les dificultats econòmiques i el problema de l'absentisme, afavorits pels canvis econòmics i socials, i contra els quals es lluità tant des de l'Església local com des del bisbat. Finalment, a través de l'escola parroquial i de la seva ascendència -malgrat la creixent rivalitat amb els jurats- sobre la de gramàtica, la parròquia exercí un notable paper en la formació (a banda del propi clergat) d'una elit laica intel-lectualment i moralment ben preparada per ocupar càrrecs importants, també en la nova societat. Com s'esdevingué en altres parròquies, adaptant-se als canvis i malgrat les dificultats, aquests foren els mecanismes fonamentals que permeteren a l'Església local intentar mantenir, en una societat en transformació, l'exercici d'un autèntic monopoli de la paraula que li possibilités, amb la màxima eficiència, la seva direcció espiritual i la seva mediació moral i cultural.

sobre Matoses, germà del ferrer-menescal de Piera Jaume Matoses, vegeu Josep M. MADURELL I MARIMOn i Jordi RUBIÓ I BALAguer, Documentos para la historia de la imprenta y librería en Barcelona (1474-1553). Barcelona, 1955, pp. 76-77 i 464-65.

Tot $i$ que no té a veure amb graus universitaris, un altre cas documentat d'un pierenc treballant fora de la vila després d'haver fet els primers estudis a Piera és el de Ramon Basset. copista professional de llibres, contractat (1260) per Berenguer d'Espiells, precentor de la catedral de Barcelona (vegeu Josep MAS I DOMĖNECH. Notes documentals de llibres antichs a Barcelona, "BRABLB". 8 [1915-1916], pp. 155-67, 238-51, 330-45, 400-06, i 444-63, a les pp. 163-64): un Guillem Basset signà com a testimoni l'acta de consagració de la nova església parroquial del mateix any (vegeu la nota 24). 


\section{RÉSUMÉ}

On étudie dans ce travail, avec une documentation pour la plupart inédite, le contrôle simultané sur les milieux spirituel, éducationnel et notarial exercé par une paroisse catalane dans une petite ville en expansion (Santa Maria de Piera, évêché de Barcelone) à la fin du Moyen Âge. On relie ces trois milieux de contrôle, en les présentant comme les mécanismes fondamentaux qui ont permis à l'Église locale d'essayer de maintenir, dans une société changeante, l'exercice d'un véritable monopole de la parole qui lui rendait possible, avec la plus grande efficacité, sa direction spirituelle et sa médiation morale et culturelle.

\section{SUMMARY}

Using largely unpublished documentation, this article studies the spiritual, educational, and notarial control exercized by the parish of an expanding, late-medieval Catalan town (Santa Maria de Piera, in the bishopric of Barcelona). These three related areas of control are viewed as the basic mechanisms that allowed the local church to maintain a monopoly of the word. It was this monopoly that, even in the face of a changing society, enabled the local church efficiently to maintain its directing role in spiritual guidance and in mediating cultural and moral ideals. 